\title{
Plant Vogtle Cooling Tower Studies
}

\author{
by \\ L. O'Steen \\ Westinghouse Savannah River Company \\ Savannah River Site \\ Aiken, South Carolina 29808 \\ E. Villa \\ R. Kurzeja \\ M. Pendergast
}

A. Garrett

This paper was prepared in connection with work done under the above contract number with the U.S. Department of Energy. By acceptance of this paper, the publisher and/or recipient acknowledges the U.S. Government's right to retain a nonexclusive, royalty-free license in and to any copyright covering this paper, along with the right to reproduce and to authorize others to reproduce all or part of the copyrighted paper. 
May 1999

WSRC-TR-99-00174(U)

\title{
Plant Vogtle Cooling, Tower Studies (U)
}

\author{
Lance $O^{\prime}$ Steen \\ Eliel Villa \\ Robert Kurzeja \\ Malcolm Pendergast \\ Alfred Garrett
}

Savannah River Technology Center

Publication Date: May 1999

DOES NOT CONTAIN

UNCLASSIFIED CONTROLLED

NUCLEAR INFORMATION

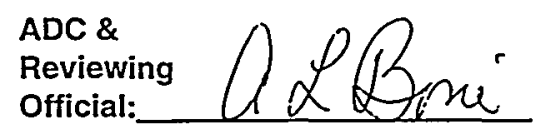

Official:

Date: $1-05-2000$ 


\section{May 1999}

\section{Westinghouse Savannah River Company Savannah River Site Aiken, SC 29808}

\section{DISCLAIMER}

This report was prepared as an account of work sponsored by an agency of the United States Government. Neither the United States Government nor any agency thereof, nor any of their employees, makes any warranty, express or implied, or assumes any legal liability or responsibility for the accuracy, completeness, or usefulness of any information, apparatus, product or process disclosed, or represents that its use would not infringe privately owned rights. Reference herein to any specific commercial product, process or service by trade name, trademark, manufacturer, or otherwise does not necessarily constitute or imply its endorsement, recommendation, or favoring by the United States Government or any agency thereof. The views and opinions of authors expressed herein do not necessarily state or reflect those of the United States Government or any agency thereof.

This report has been reproduced directly from the best available copy.

Available for sale to the public, in paper, from: U.S. Department of Commerce, National Technical Information Service, 5285 Port Royal Road, Springfield, VA 22161, phone: (800) 553-6847

fax: (703) 605.6900

email: orders@ntis.fedworld.gov

online ordering: http://www.ntis.gov/ordering.htm

Available electronically at http://www.doe.gov/bridge

Available for a processing fee to U.S. Department of Energy and its contractors, in paper, from: U.S. Department of Energy, Office of Scientific and Technical Information, P.O. Box 62, Oak Ridge, TN 37831-0062, phone: (865) 576-8401

fax: (865) 576-5728

email: reports@adonis.osti.gov 


\section{DISCLAIMER}

Portions of this document may be illegible in electronic image products. Images are produced from the best available original document. 
WSRC-TR-99-00174

May 1999

DOCUMENT: $\quad$ WSRC-TR-99-00174

TITLE: $\quad$ Plant Vogtle Cooling Tower Studies (U)

TASK:

7

TECHNICAL REVIEW

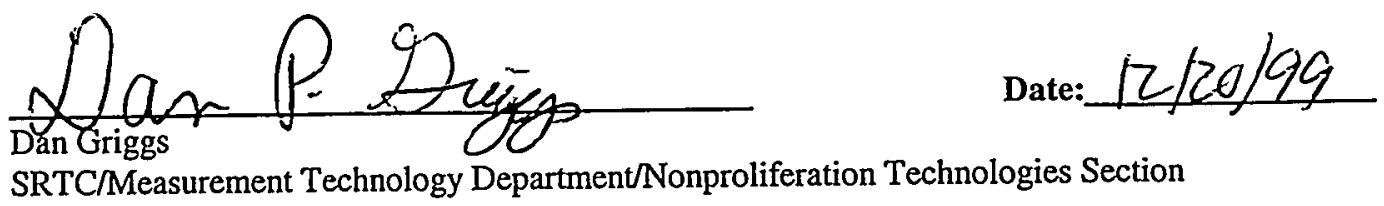

APPROVALS
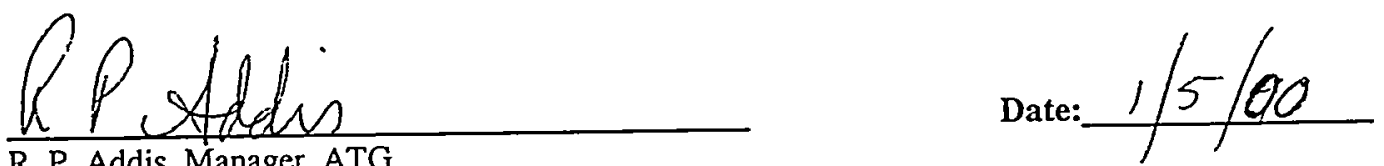

R. P. Addie, Manager, ATG

SRTC/Measurement Technology Department/Nonproliferation Technologies Section

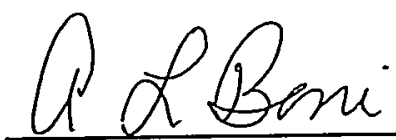

Date: $1-0.5-2000$

A. L. Bon, Manager, NTS

SRTC/Measurement Technology Department/Nonproliferation Technologies Section

3 


\section{WSRC-TR-99-00174}

\section{May 1999}

\section{Summary}

Intensive ground-based field studies of plumes from two large, natural-draft cooling towers were conducted in support of the MTI modeling effort. Panchromatic imagery, IR imagery, meteorological data, internal tower temperatures and plant power data were collected during the field studies. These data were used to evaluate plume simulatións, plume radiative transfer calculations and plume volume estimation algorithms used for power estimation. Results from six field studies indicate that a 3-D atmospheric model at sufficient spatial resolution can effectively simulate a cooling tower plume if the plume is of sufficient size and the ambient meteorology is known and steady. Small plumes and gusty wind conditions degrade the agreement between the simulated and observed plumes. Thermal radiance calculations based on the simulated plumes produced maximum $\mathbb{R}$ temperatures (near tower exit) which were in good agreement with measured $\mathbb{R}$ temperatures for the larger plumes. For the smaller plumes, the calculated $\mathbb{R}$ temperature was lower than the measured temperature by several degrees. Variations in maximum $\mathbb{R}$ plume temperature with decreasing power (one reactor was undergoing a shutdown process), were clearly observed in the IR imagery and seen in the simulations. These temperature changes agreed with those calculated from an overall tower energy and momentum balance. Plume volume estimates based on camcorder images at three look angles were typically $20-30 \%$ larger than the plume volumes derived from the simulations, although one estimate was twice the simulated volume. Volume overestimation is expected and will have to be accounted for to some degree if plume volume is to be a useful diagnostic quantity in power estimation. Volume estimation with MTI imagery will require a large, stable plume and two looks in the visible bands (5m GSD) along with a solar shadow. 


\section{May 1999}

\section{Introduction}

One application of the Multispectral Thermal Imager (MTI) project is power estimation for a generating facility based on imagery of the facility's cooling tower plume(s) and numerical plume simulations. The proposed methodology (see Power Estimation section) for power estimation involves comparison of MTI imagery and plime volume(s) derived from imagery with numerical simulation of the physical, thermodynamic and radiative properties of the plume(s). In support of this MTI application, six cooling tower studies were conducted at the Vogtle Nuclear Plant near Augusta, Georgia during the spring of 1998. These studies were designed to test the feasibility of using high-resolution, 3-D plume simulations and visible/infrared $(\mathbb{R})$ imagery at three view angles to estimate plant operating power. The date and local time, power levels and ambient meteorological conditions are given below in Table 1.

Table 1.

Date Local
Time

12-18-97

02-19-98

02-26-98

03-04-98

03-26-98

04-02-98
Cooling Tower Power

$\begin{array}{cc}\text { Tower } 1 & \text { Tower } 2 \\ \text { MW } & \text { MW }\end{array}$

2331

2329

2329

2325

2330

2336

2322

2182

2037

1865

1300

1145

0

0
Surface Meteorology

$\begin{array}{ccc}\text { Temperature } & \text { Humidity } & \text { Wind Speed } \\ \mathrm{C} & \mathrm{g} / \mathrm{kg} & \mathrm{m} / \mathrm{s}\end{array}$

16.2

17.8

19.0

13.0

23.0

24.4
3.4

5.5

1.0

5.7

3.5

3.0

2.0

6.7

4.5

4.6

Note that the power for tower 2 declined for the $2 / 19,2 / 26$ and $3 / 4$ data collections as the plant prepared for the refueling of unit 2 . This provided a unique opportunity to study plumes at different power levels, but with the same ambient meteorology. Tower 2 was shutdown completely during the final two field experiments. The shutdown of unit 2 provided an opportunity to check the proposed power estimation . methodology for potential problems related to plume interaction. All data collection was ground based and included: panchromatic imagery, thermal imagery, surface and upper air meteorology, internal tower temperature, and plant power data. These data were utilized.in conjunction with high resolution, 3-D plume simulations, a plume volume reconstruction algorithm and plume radiance calculations to evaluate the feasibility of estimating power from cloud water plume imagery. Power estimation for cooling towers without a cloud water plume (hot, dry ambient conditions) is not considered here.

\section{Power Estimation}

Cooling tower power estimation is based on an energy balance for the air stream flowing through the tower:

$$
P=Q\left(H_{\text {out }}-H_{\text {in }}\right)
$$

where: $Q=$ mass flow rate through the tower

$\mathrm{H}_{\text {in }}=$ enthalpy of the ambient air entering the bottom of the tower

$\mathrm{H}_{\mathrm{out}}=$ enthalpy of the air exiting the top of the tower

Water loss due to evaporation and the addition of make-up water is ignored in the above equation.

The enthalpy terms in the above equation are dependent on the temperature and humidity of the associated air streams. The tower exit stream for a visible plume is saturated, and thus its enthalpy is a function of temperature only. If the ambient air temperature and humidity near the ground can be determined (tower inlet enthalpy), then the cooling tower power is a function of exit flow rate and temperature. An overall 


\section{May 1999}

momentum balance on the air stream can be utilized for a natural draft cooling tower, if the overall tower friction can be estimated.

$$
w^{2}=\left(2 \mathrm{gZ} / \mathrm{c}_{\mathrm{d}}\right)\left(\rho_{\text {in }}-\rho_{\text {out }}\right) / \rho_{\mathrm{m}}
$$

where: $\rho$ - density of dry air-vapor mixture

$\mathrm{Z}$ - tower draft height

$c_{d}$ - overall drag coefficient for the tower

$w$ - mean air velocity through the tower

$\rho_{\mathrm{m}}-$ mean air density in the tower

The largest pressure drop in the momentum balance occurs in the packing section, and is controlled by the total water load and water load distribution. The momentum balance relates the mean tower velocity to exit air temperature and ambient air density. A plot of tower exit temperature versus tower velocity, parameterized by power (energy balance) and by friction (momentum balance) is shown in Figure 1. In general, direct power estimation requires remote measurement of exit tower velocity and temperature. If an overall tower momentum balance can be utilized, then velocity (or temperature) can be eliminated as an independent variable. In this case, power is a function of only tower exit temperature (or velocity), assuming that the ambient conditions are known. Of course, uncertainty in the estimation of a friction . coefficient for the tower must now be considered.

Both tower velocity and exit air temperature are difficult to measure remotely. Velocity measurements cannot be made with visible/IR imagery and IR-derived temperature measurements will depend on a path integral involving transmitted, scattered and absorbed/emitted radiation through the cloud water plume in a specified direction. Surface and air emissions might also have to be taken into account since the cloud water plume can be a source of $\mathbb{R}$ scattering. The magnitudes of these radiation components depend on the local plume temperature, cloud water concentration, droplet number density and droplet size distribution as well as radiation wavelength. Plume temperature and cloud water concentration vary rapidly with height . above the tower. Significant variations also exist in the cross-plume direction. Only a small, core region of the cloud water plume, very near the tower exit, is at the outlet air temperature required in the power equation. Thus, it is unlikely that the tower outlet air temperature can be directly measured from an $\mathbb{R}$ image if an optically thick cloud water plume exists. It might be possible to directly obtain a reasonable estimate of the tower exit temperature with very high spatial resolution $\mathbb{R}$ imagery and the right combination of view angle and plume orientation (tower temperature corresponds to the brightest pixel). In general, plume temperatures derived from IR imagery will be low relative to the desired "power " temperature, since the thermal radiance will be strongly impacted by radiative transfer through cooler regions of the plume far from the tower exit. Thus, the highest $\mathbb{R}$ temperature in a high-resolution image should represent a lower bound on the true exit air temperature. With only a lower bound on tower temperature and a reasonable range for flow rate, power estimates will exhibit a large uncertainty (see Figure 1). However, it might be possible to estimate the actual "power" temperature from IR imagery by utilizing high-resolution plume simulations and radiance calculations derived from these simulations; the tower exit temperature (input to the plume simulation) would be adjusted to obtain agreement between . calculated plume radiance and measured radiance. Unfortunately, this would still leave a lot of uncertainty in the power estimate due to a lack of information on tower flow rate. More information is needed to reduce this uncertainty. The use of plume volume as a replacement for tower velocity is discussed below.

The enthalpy difference in the energy balance is largely due to latent heat from evaporating water. Thus the amount of water vapor available for condensation into a cloud water plume should be related to the operating power of the cooling tower. Atmospheric conditions above the tower and the mixing rate between the ambient atmosphere and the developing plume will determine how much of the available water vapor is actually condensed into a visible plume. This idea can be illustrated using the psychrometric plot in Figure 2 for an atmosphere which is vertically homogeneous. The area between the mixing line and saturation curve is indicative of the potential for cloud water formation. Details of the plume-ambient air mixing process determine the thermodynamic state of the rising plume along the mixing curve. If the visible plume volume can be estimated from imagery taken at multiple view angles (either $\mathbb{R}$ or visible), then this might 


\section{WSRCं-TR-99-00174}

\section{May 1999}

be useful in estimating power. In other words, replace tower exit velocity with plume volume in the power estimation methodology. Of course, knowledge of the vertical structure of the atmosphere above the cooling tower (mixing) now enters the problem and this will be an additional source of uncertainty. Highresolution plume simulations indicate that plume volume is a function of tower exit air temperature and velocity for a given ambient meteorology; these tower exit conditions provide a source term for the plume. . However, this dependence is not the same as for power. This is illustrated in Figure 3, where simulated cloüd water plume volume versus power is plotted for the friction factors of Figure 1. For a given power, the larger friction factor simulations (higher exit air temperatures) produce larger plume volumes. This is not surprising since the water vapor content of saturated air increases rapidly with increasing air temperature. In Figure 4, tie-lines of constant volume are included in the results of Figure 1. These tielines were generated from numerical plume simulations at different tower exit temperatures and velocities along the indicated operating curves (tower frictions of 2.0 and 6.5).

Figure 4 suggests how plume volume measurements can be used to improve power estimates. Assume that there is an $\mathbb{R}$ temperature measurement derived from the hottest pixel in the image, and that this is taken as a lower bound on the true exit air temperature. Plume simulations and radiance calculations presented in the following sections of this report indicate that the true tower exit temperature is probably $5-8^{\circ} \mathrm{C}$ above the maximum IR value. Based on the cooling tower design, a range of tower velocities can also be assumed. For a natural draft tower, this might be $3-7 \mathrm{~m} / \mathrm{s}$. If the measured IR temperature is $297^{\circ} \mathrm{K}$, then (from figure 4) the range of powers consistent with the assumed tower temperature and velocity ranges would be 1400 to $3900 \mathrm{MW}$. However, if the plume volume was also measured and found to be $2.6 \times 10^{6}$ $\mathrm{m}^{3}$, then the power range estimate would be 2900 to $3200 \mathrm{MW}$. This represents a significant improvement in the power estimate, although uncertainty in the measured plume volume has not been considered and will undoubtedly expand the estimated power range. If the tower exit temperature can be deduced from the IR imagery (directly or with plume/radiance simulation), then the combination of plume volume and tower exit temperature yields an estimate of power.

The above techniques for improving power estimation require 3-D, high-resolution plume simulations, plume radiance calculations and plume volume reconstruction based on multiple look imagery. The data collections described below were designed to test these capabilities. No attempt was made to estimate a power from the collected data and then compare this estimate with the known power. This would be quite time consuming for 6 collections. Instead, energy and momentum balance calculations were made for the known power levels and with tower friction factors of 2.0 and 6.5. The tower exit air temperatures and velocities from these calculations were then used as input to plume simulations for each collection. Results based on these plume simulations were then compared to the collected data. Previous studies of the Vogtle cooling towers suggest that these results should bracket the actual plume behavior (O'Steen, 1995).

\section{Computational Algorithms}

The Regional Atmospheric Modeling System (RAMS) developed at Colorado State University was utilized for plume simulations. RAMS is a 3-D, nonhydrostatic boundary-layer model developed primarily for simulating mesoscale circulations (Tripoli and Cotton, 1982). However, RAMS has also been used for large-eddy simulations and high-resolution flow around simple structures (Nicholls, et al, 1993). RAMS has a 2-way interactive grid nesting capability which allows successively higher resolution grids to be created within an initial coarse resolution simulation domain. In the current simulations, five grids were utilized, with the outermost grid encompassing a $150 \mathrm{~km} \mathrm{x} 150 \mathrm{~km}$ domain at $5 \mathrm{~km}$ resolution and the innermost grid encompassing a $1 \mathrm{~km} \times 1 \mathrm{~km}$ domain at $20 \mathrm{~m}$ resolution. The plume simulation occurs on this innermost grid. Given a tower exit diameter of 80 meters, the plume simulations in this study are capable of resolving the larger eddies responsible for plume mixing. Mixing at smaller scales is based on a parameterization utilizing the turbulent kinetic energy and a length scale related to the grid size. Plume simulations were run for 15 minutes with results saved at 1 minute intervals. The plume was created by adding "nudging" terms to the energy, momentum and moisture equations in RAMS. These terms drive the temperature, velocity and humidity at specified grid points (virtual tower) to values corresponding to a desired power level. This methodology is based on standard data assimilation techniques (Stauffer and 


\section{May 1999}

Seaman, 1990). Details of this "nudging" method as applied to plume simulation can be found in O'Steen, 1995.

Plume radiance was calculated utilizing a 2-stream method with Mie coefficients determined from cloud water properties extracted from RAMS simulations. Rays were defined through the cloud volume at a specified angle. Along each ray, cloud water number density and droplet size were interpolated from the plume simulation and used to compute extinction coefficients, scattering coefficients and asymmetry factor from Mie theory at a specified wavelength. Emission was computed from the Planck equation using interpolated temperatures. The radiative transfer equations were then solved along each ray to produce a radiance image for both stream directions. Most of these calculations were performed for a wavelength of $10 \mu \mathrm{m}$. Cloud water droplet sizes were assumed to follow a gamma distribution with a droplet number density of $300 \mathrm{~cm}^{-3}$. Studies of continental clouds indicate that the droplet number density varies from 200 $\mathrm{cm}^{-3}$ (coastal) to $700 \mathrm{~cm}^{-3}$ (mid-continent). Varying the droplet density between 200 and $400 \mathrm{~cm}^{-3}$ produced little change in the plume radiance results reported here. Mean droplet diameter for a cloud water plume was typically 5 to $15 \mu \mathrm{m}$, depending on cloud water content.

Plume volume was estimated from camcorder images at three different viewing angles. The basic idea is as follows: create a computational array of volume elements large enough to encompass the plume, and then determine which of those volume elements have azimuth and elevation angles, relative to a particular observation location, such that they could possibly be a part of the plume image acquired at that location. This algorithm requires accurate locations of the observation points, the location of a reference point in each image and a feature of known length within each image. The plume boundary must be determined for each image. This is done interactively by graphically tracing the plume boundary in each image. The algorithm for determining which volume elements are within the plume allows for extremely convoluted plume shapes, but the plume boundary must be contiguous. This type of volume reconstruction will systematically reduce the estimated plume volume as more images from different observation locations are analyzed. The true plume volume will always be overestimated by this method.

\section{Data Collection}

The panchromatic imagery was obtained with standard camcorders at 3 locations. A map of Plant Vogtle and the surrounding area, with the camcorder locations, is shown in Figure 5. The locations were chosen to provide widely spaced view angles, an unobstructed view of the tower tops and a field-of-view that could accommodate a reasonable range of plume sizes. These features are important for the volume reconstruction algorithm based on analysis of camcorder images. Accurate locations of the camcorders and cooling towers were determined by differential GPS. A theodolite was used to obtain accurate elevations at each observation location relative to the tower tops. Camcorder imagery was collected simultaneously for approximately 10 minutes during each experiment. Four images were selected from each camera for volume reconstruction. All images were stored as $640 \times 480$ tiff files.

Thermal IR imagery was collected with an Inframetrics 760 camera operating in the 8-12 $\mu \mathrm{m}$ spectral band. The location of the $\mathbb{R}$ camera during all collections is indicated in Figure 5. The Inframetrics camera has a field of view of $15^{\circ}$ vertical $\times 20^{\circ}$ horizontal with a $4 \mathrm{X}$ continuously adjustable E-O Zoom. The camera location was such that the top section of the tower wall as well as the entire plume could be imaged.

Surface meteorology was obtained from SRS towers at levels between 2 and $60 \mathrm{~m}$ AGL. These towers are located just off the map at the east boundary in Figure 5. These data were used to initialize the atmospheric/plume simulation and to define the enthalpy (wet bulb temperature) of the air stream entering the cooling towers. Upper air meteorology was obtained from regional soundings at $12 \mathrm{z}(0800 \mathrm{LT})$ and from a nearby TV tower instrumented at 8 levels to $300 \mathrm{~m}$ AGL; cooling tower tops are at $167 \mathrm{~m}$ AGL. A tethersonde was also flown during the $3 / 26$ and $4 / 2$ collections; wind speed and direction, temperature and humidity were collected from ground level to $450 \mathrm{~m}$ AGL. The TV tower data did not include humidity. However, all upper air data indicated that a well-mixed boundary-layer (at least to 500m AGL) existed 


\section{WSRC-TR-99-00174}

\section{May 1999}

during the collections, and thus humidity at $60 \mathrm{~m}$ was deemed appropriate for initializing the boundary-layer (along with sounding data) when tethersonde data was unavailable.

Power data were provided by Plant Vogtle at hourly intervals. These data included thermal reactor power and gross electric power for both units. Normal reactor power (100\%) was $3563 \mathrm{MW}$ for both units. Gross electric power varied between 1220 and $1240 \mathrm{MW}$. Thus cooling tower energy dissipation was typically about $2330 \mathrm{MW}$ at full reactor power.

Measurement of temperature inside the cooling towers was attempted for all collections after $2 / 19$. Initial measurements were made with a hand-held thermocouple located just above the drift eliminator. Data were collected at numerous locations within the tower since inhomogeneites in packing and water loading produce significant variations in air velocity and temperature. Temperature variations of $7^{\circ} \mathrm{C}$ over distances of a few meters were not uncommon. An average temperature could be determined from these data, but was suspect since only locations along the walkways could be sampled. In an effort to obtain an appropriate tower exit temperature for power calculations, it was decided to make elevated measurements of temperature by flying small sounding balloons inside the tower. The small length scale for observed temperature fluctuations at the drift eliminators suggested that mixing should produce a reliable average temperature $30 \mathrm{~m}$ above the drift eliminators. Unfortunately, this was not found to be the case. The temperature frequently appeared to decline by $2-4^{\circ} \mathrm{C}$ as the balloon ascended to the $30 \mathrm{~m}$ level and a $7^{\circ} \mathrm{C}$ horizontal variation (at $30 \mathrm{~m}$ ) was observed during a transect of the tower. It is speculated that cool, dry outside air entering the tower as a high velocity jet along the inside periphery is creating this elevated temperature distribution. If this is the case, then temperature measurements will have to be made at higher elevations within the tower.

\section{Results}

The following results are given in Table 2 below: computed tower exit temperatures for tower friction coefficients of 2.0 and 6.5 (energy and momentum balance), measured and simulated $\mathbb{R}$ plume temperatures at the tower exit, internal tower temperatures estimated from temperature surveys within tower 2 (tower 1 on $3 / 26$ and 4/2), total plume volume from image analysis, simulated plume volume for the above friction coefficients.

\section{Table 2}

\begin{tabular}{|c|c|c|c|c|c|c|c|c|c|}
\hline \multirow{2}{*}{$\begin{array}{r}\text { Date } \\
\text {. }\end{array}$} & \multicolumn{2}{|c|}{ Power } & \multicolumn{2}{|c|}{$\begin{array}{l}\text { Computed } \\
\text { Tower } \\
\text { Temperature }\end{array}$} & \multicolumn{2}{|c|}{$\begin{array}{c}\text { IR Exit Plume } \\
\text { Temperature } \\
\text { (measured / simulated) }\end{array}$} & \multirow{2}{*}{$\begin{array}{c}\text { Measured } \\
\text { Tower } \\
\text { Temp. } \\
\\
\text { K } \\
(2)\end{array}$} & \multirow{2}{*}{$\begin{array}{l}\text { Simul } \\
\text { Vol. } \\
\text { (total) } \\
\times 10^{6} \\
\mathrm{M}^{3} \\
(1)\end{array}$} & \multirow{2}{*}{$\begin{array}{c}\text { Recon. } \\
\text { Vol. } \\
\text { (total) } \\
\times 10^{6} \\
\mathrm{M}^{3}\end{array}$} \\
\hline & $\begin{array}{l}\text { Twr } 1 \\
\text { MW }\end{array}$ & $\begin{array}{c}\text { Twr } 2 \\
\text { MW }\end{array}$ & $\begin{array}{c}\text { Twr } 1 \\
\underset{(1)}{K}\end{array}$ & $\begin{array}{c}\text { Twr } 2 \\
\mathrm{~K} \\
(1)\end{array}$ & $\begin{array}{c}\text { Twr } \\
\mathrm{K}\end{array}$ & $\begin{array}{c}\text { Twr } 2 \\
\mathrm{~K}\end{array}$ & & & \\
\hline $12-18-97$ & 2331 & 2322 & $\begin{array}{l}307.2 \\
302.2\end{array}$ & $\begin{array}{l}307.2 \\
302.2\end{array}$ & $---/ 298$ & ----/ 298 & -..- & $\begin{array}{l}3.8 \pm .4 \\
2.8 \pm .3\end{array}$ & $3.3 \pm .4$ \\
\hline $02-19-98$ & 2329 & 2182 & $\begin{array}{l}308.9 \\
303.9\end{array}$ & $\begin{array}{l}308.2 \\
303.3\end{array}$ & $297.4 / 297$ & $297.4 / 297$ & --- & $\begin{array}{l}3.3 \pm .3 \\
1.9 \pm .2\end{array}$ & $3.2 \pm .4$ \\
\hline $02-26-98$ & 2329 & 2037 & $\begin{array}{l}309.4 \\
304.5\end{array}$ & $\begin{array}{l}308.0 \\
303.3\end{array}$ & $299.4 / 301$ & $298.0 / 297$ & 306 & $\begin{array}{l}2.4 \pm .4 \\
1.6 \pm .3\end{array}$ & $2.5 \pm .3$ \\
\hline $03-04-98$ & 2325 & 1865 & $\begin{array}{l}306.3 \\
300.9\end{array}$ & $\begin{array}{l}303.8 \\
298.8\end{array}$ & $294.8 / 295$ & $292.5 / 293$ & 303 & $\begin{array}{l}1.8 \pm .2 \\
1.5 \pm .2\end{array}$ & $4.0 \pm 1$ \\
\hline $03-26-98$ & 2330 & 0 & $\begin{array}{l}311.6 \\
307.1\end{array}$ & ---- & $302.3 / 299$ & -...- & 308 & $\begin{array}{l}.36 \pm .03 \\
.38 \pm .05\end{array}$ & $.48 \pm .07$ \\
\hline $04-02-98$ & 2336 & 0 & $\begin{array}{l}311.3 \\
306.7\end{array}$ & ---- & $302.0 / 299$ & ---- & 308 & $\begin{array}{l}.30 \pm .03 \\
.29 \pm .03\end{array}$ & $.51 \pm .05$ \\
\hline
\end{tabular}

(1) Two values are given for each collection in this column; the top value is for a tower friction of 6.5 , the 
WSRC-TR-99-00174

May 1999

value below it is for a tower friction of 2.0 .

(2) Only tower 2 if both towers are operating.

The results in Table 2 are also presented in Figure 6 , with the abscissa representing the 6 collection dates. The "power" temperature is the average of the calculated tower exit temperatures for tower frictions of 2.0 and 6.5. The measured tower temperature is taken from temperature surveys above the drift eliminators . within tower 1or 2 . The measured $\mathbb{R}$ temperature is derived from imagery collected with the Inframetrics camera $(8-12 \mu \mathrm{m})$. This temperature is a 10-minute average of a single pixel in the cloud water plume, at a point directly above the center of each cooling tower. The calculated IR temperature is the Planck function temperature at $10 \mu \mathrm{m}$ corresponding to the average maximum radiance computed for the simulated plumes. The radiation path for this calculation was chosen to correspond to the observation direction for the measured $\mathbb{R}$ temperature. A radiance of $4.0 \mathrm{~W} / \mathrm{m}^{2}$-sr- $\mu \mathrm{m}$ was utilized in these calculations to represent a clear sky background; this corresponds to a Planck temperature of $252^{\circ} \mathrm{K}$ at $10 \mu \mathrm{m}$. A radiance of 9.0 $\mathrm{W} / \mathrm{m}^{2}$-sr- $\mu \mathrm{m}\left(290^{\circ} \mathrm{K}\right)$ was used for surface emissions. Plume simulation results at three separate times were used to determine the maximum radiance reported for each collection date. Only the plume simulations for a tower friction of 6.5 ( high tower exit temperature) were used in the radiance calculations. Radiance results for a tower friction of 2.0 yielded IR temperatures that were 4 to 5 degrees cooler.

Simulated cloud water plume volumes, for both tower friction factors, are an average over 10 simulations at 1-minute intervals. In Figure 6, cloud water plume volumes for the single tower collections on 3/26 and 4/2 have been increased by a factor of 2 to be consistent with the other collections ( 2 towers operating). The saturation deficit of the ambient air at the tower top (from simulation) is also given in Figure 6 since it is generally assumed to be correlated with plume size.

The measured tower temperature is about $1^{\circ} \mathrm{C}$ lower than the calculated "power" temperature for all collections. Recall that the "power" temperature is an average of the tower exit air temperatures for tower frictions of 2.0 and 6.5. The temperature difference between these tower frictions is about 5 degrees for all the collections. As expected, the variation in the measured tower temperature closely tracks the variations in the surface air temperature. While not given in Table 2 or Figure 6 , the computed tower exit velocities were in the range of 3 to $6 \mathrm{~m} / \mathrm{s}$. This is typical for large natural draft cooling towers. These results support the selection of tower frictions for the Vogtle cooling towers.

The measured IR temperatures are based on radiances in the $8-12 \mathrm{~mm}$ band, and are reported directly by the Inframetrics system based on an emissivity of 1.0 (user specified). The calculated maximum $\mathbb{R}$ temperatures, based on plume simulations, are approximately equal to the measured $\mathbb{R}$ temperatures for the $2 / 19,2 / 26$ and $3 / 4$ collections. For the final 2 collections, the calculated maximum $\mathbb{R}$ temperatures are lower than the measured temperatures by about $3^{\circ} \mathrm{C}$. Note that the variations in both IR temperatures mirror those of the measured tower temperatures. This indicates that the IR temperatures are primarily responding to the tower exit temperatures. However, the difference in the IR temperatures for the $3 / 26$ and $4 / 2$ collections suggests that the plume volume is also a factor since the plumes on these dates were much smaller than the previous collections. The low calculated $\mathbb{R}$ temperatures are almost certainly related to the small optical depths generated by these plume simulations.

The measured plume volumes from image reconstruction are always larger than the simulated plume volumes. Recall that the simulated plume volumes in Figure 6 are an average of the results for both tower frictions. This bias is expected since the volume reconstruction algorithm used in this study always overestimates the true plume volume. While the amount of this overestimation has not been determined, the volume errors for $3 / 4$ and $4 / 2$ are certainly excessive.

The above results, as well as input data and computations used to generate the results, are discussed below for each collection. 


\section{WSRC-TR-99ी-00174}

\section{May 1999}

Only camcorder imagery, SRS tower data and regional sounding data were collected during this initial study. The camcorder positions at this time were much closer to the towers than those in subsequent collections. These locations are numbered 1,2 and 3 in Figure 5. Camcorder images were recorded between 1340 and 1350 local time (1840 1850 Z). The boundary-layer/plume simulation (RAMS) was initialized at $18 \mathrm{Z}$ with ETA model forecast fields generated from $12 \mathrm{Z}$ data (i.e. a $6 \mathrm{~h}$ ETA forecast). In Figure 7, vertical profiles of temperature and humidity generated by RAMS at $19 \mathrm{Z}$ are compared with SRS tower data and with the Atlanta sounding at $0 Z$ on $12 / 19$. The RAMS simulation appears to capture the basic structure of the boundary layer quite well. Both the Atlanta sounding and simulation results indicate a boundary layer depth of about $1 \mathrm{~km}$. RAMS underpredicts the observed temperatures by about $1^{\circ} \mathrm{K}$ for heights below $500 \mathrm{~m}$ AGL, and closely reproduces the observed humidity in the boundary-layer. Since the sounding data were collected in the early evening on $12 / 18$, the sounding temperatures near the surface are cooler than the SRS data, which was collected at 1400 local time. This is particularly evident in the lowest level data.

Plume simulations are shown in Figure 8 along with actual plume images. The effect of low ambient wind velocity on plume geometry is evident. Plume simulations were performed at power levels of 1900,2325 , and $2900 \mathrm{MW}$ for tower friction coefficients of 2.0 and 6.5. Tower inlet air conditions are as indicated in Table 1. Calculated exit air temperatures for both tower frictions are given in Table 2. A plot of simulated plume volume versus power for both friction coefficients is shown in Figure 9.

The reconstructed plume volume was calculated to be $3.3 \times 10^{6} \mathrm{~m}^{3} \pm 0.4 \times 10^{6} \mathrm{~m}^{3}$. This uncertainty is based on the analysis of 3 sets of plume images. The reconstructed plume volume estimate lies between the simulated volumes at $2325 \mathrm{MW}$ and exhibits an uncertainty similar to that found for the simulations. Since the reconstructed plume volume overestimates the true volume, this result suggests that the correct tower friction is probably closer to 2.0 than 6.5 . Small plume sizes and extremely light winds aloft prevented plume merging, and allowed for separate volume estimates. Average plume volumes for towers 1 and 2 were $1.4 \times 10^{6} \mathrm{~m}^{3}$ and $1.9 \times 10^{6} \mathrm{~m}^{3}$, respectively. This disparity was not seen in the simulations and probably resulted from slightly different conditions within the towers.

Although $\mathrm{IR}$ imagery was not collected during this initial study, radiative transfer calculations were still performed since the plume geometry, resulting from low wind conditions aloft, was rather unique. Simulated $\mathbb{R}$ images at $10 \mu \mathrm{m}$ based on the plume simulation for $2325 \mathrm{MW}$ and a friction coefficient of 6.5 are shown in Figures 10 and 11 for nadir and $90^{\circ}$ off-nadir views. Background radiances were not imposed on these radiance calculations. This was done to isolate the effect of the plume and illustrate the difference between space and ground-based look angles. The large difference in plume size is due to the calm wind conditions imposed on the plume simulation. The frequency distributions of radiance for these two images are given in Figures 12 and 13. Radiances of 8 and $9 \mathrm{~W} / \mathrm{m}^{2}-\mathrm{sr}-\mu \mathrm{m}$ correspond to $\mathbb{R}$ temperatures of 287 and $294^{\circ} \mathrm{K}$ at $10 \mu \mathrm{m}$. Based on these frequency distributions, the maximum $\mathbb{R}$ temperatures for the nadir and $90^{\circ}$ off-nadir views were approximately $289.3^{\circ} \mathrm{K}$ and $291.4^{\circ} \mathrm{K}$, respectively. The simulated exit plume temperature was $307.2^{\circ} \mathrm{K}$ (see Table 2) and the ambient atmospheric temperature above the tower varied from $286^{\circ} \mathrm{K}$ at the top of the tower to about $283^{\circ} \mathrm{K}$ at $300 \mathrm{~m}$ above the tower. Thus the simulated maximum $\mathbb{R}$ temperatures appear to be reasonable based on the ambient temperature and a normal thermodynamic plume structure. The $90^{\circ}$ off-nadir temperature is higher than the nadir temperature since it represents a path integrated $\mathbb{R}$ temperature between the core and outside edge of the cloud water plume at the tower exit $\left(307\right.$ to $286^{\circ} \mathrm{K}$ ); much of this path is at temperatures above $300^{\circ} \mathrm{K}$. The nadir view temperature is an average between the tower exit and the top of the plume ( 307 to $283^{\circ} \mathrm{K}$ ); a distance of at least 300 meters, with much of the radiative path at temperatures below $300^{\circ} \mathrm{K}$. No significant difference in radiance was found between the two radiative stream directions for the $90^{\circ}$ off-nadir view. This also seems reasonable since the simulated plumes were created in a low wind environment; hence, strong crossplume symmetry. A plot of temperature, extinction optical depth and radiance along a ray (forward and backward) near the tower exit is shown in Figure 14. Radiative transfer calculations for the $90^{\circ}$ off-nadir view were also performed with background radiances of 4.0 and $9.0 \mathrm{~W} / \mathrm{m}^{2}-\mathrm{sr}-\mu \mathrm{m}$ (sky and ground radiances) to better represent an actual ground-based, low-angle view of the plume. Calculated maximum $\mathbb{R}$ temperatures reported in Table 2 are based on these results. The radiance frequency distribution 


\section{WSRC-TR-99-00174}

\section{May 1999}

corresponding to that shown in Figure 13, but with background radiances included, is given in Figure 15 (ground-based view). The inclusion of background radiances increases the maximum plume radiance by about $1 \mathrm{~W} / \mathrm{m}^{2}-\mathrm{sr}-\mu \mathrm{m}$. This represents a $7^{\circ} \mathrm{C}$ increase in the $\mathrm{IR}$ plume temperature as seen from the

ground.

$02 / 19 / 98$

Data were collected between 1345 and 1400 local time (1845 - 1900 Z), although only 4 minutes of camcorder imagery was usable for volume analysis due to battery problems. Camcorder positions were at the distant locations (4,5,6 in Fig. 5). Reactor unit 2 was at $94 \%$ of full power, and thus the energy dissipation in cooling tower 2 was $2182 \mathrm{MW}$. The B-L/ plume simulation for this collection period was initialized at $18 \mathrm{Z}$ with ETA model forecast fields generated from $12 \mathrm{Z}$ data (6h ETA forecast). A comparison of tower and sounding data with a vertical thermodynamic profile from the RAMS simulation is shown in Figure 16. While there is good agreement between simulated and measured temperatures $(0-$ $300 \mathrm{~m} \mathrm{AGL}$ ), the simulated humidity in the boundary-layer is clearly too high by about $0.5 \mathrm{~g} / \mathrm{kg}$. Based on previous sensitivity studies and the results for $2 / 26 / 98$ (next section), this error could lead to a $30 \%$ overprediction of plume volume. Surprisingly, the simulated volume for a tower friction of 6.5 is in good agreement with the reconstructed volume (see Table 2). If both simulated and measured volumes are overestimates, then the best tower friction for this case is certainly closer to 6.5 than to 2.0 . Recall that the plume volume results for the $12 / 18$ collection seemed to favor a tower friction of 2.0. A set of camcorder images used for volume reconstruction are shown in Figure 17. A comparison of simulated and observed plumes for a single view is shown in Figure 18.

Thermal $\mathbb{R}$ imagery was collected during this field experiment. A 10 minute average of the $\mathbb{R}$ plume temperature directly above each tower yielded average temperatures of 297.3 and $297.4^{\circ} \mathrm{K}\left( \pm 0.6^{\circ} \mathrm{K}\right)$ for towers 1 and 2, respectively. A plot of these $\mathbb{R}$ data is shown in Figure 19. Simulated maximum $\mathbb{R}$ temperatures $\left(90^{\circ}\right.$ off-nadir with background) for both towers were $297.1^{\circ} \mathrm{K}\left( \pm 1.5^{\circ} \mathrm{K}\right)$. These results are based on the analysis of 3 instantaneous plumes from the 15-minute plume simulation with a tower friction of 6.5 and background radiances included. Both simulated and calculated $\mathbb{R}$ temperatures are about $12^{\circ} \mathrm{K}$ lower than the calculated tower temperature for a tower friction of $6.5\left(309^{\circ} \mathrm{K}\right)$ and $6^{\circ}$ low for a tower friction of $2.0\left(304^{\circ} \mathrm{K}\right)$. Frequency distributions of calculated plume radiance for both radiation stream directions are shown in Figure 20.

\section{2/26/98}

Data were collected between 1100 and 1115 local time ( 1600 and $1615 \mathrm{Z})$ with the camcorders at the distant locations. Reactor unit 2 was at $88 \%$ of full power; tower 2 energy dissipation was $2038 \mathrm{MW}$. Temperature data were collected inside tower 2 at the drift eliminators, although this collection did not occur until 1500 local time due to administrative problems. The average temperature at this level in the tower was approximately $306^{\circ} \mathrm{K}$, with a spatial variability of $\pm 5^{\circ} \mathrm{K}$. The boundary-layer/plume simulation for this collection time was initialized with $12 \mathrm{z}$ ETA model analysis fields. A comparison of tower data and a vertical thermodynamic profile from the simulation is shown in Figure 21. The simulated temperatures are $1-2^{\circ} \mathrm{K}$ lower than the tower data, but the simulated humidity is in good agreement with low level measurements. Note that the surface meteorology here is very similar to that on $2 / 19$. Thus the calculated tower exit air temperature and velocity are also very similar. The difference in simulated plume volumes between the $2 / 19$ collection $\left(3.3 \mathrm{M} \mathrm{m}^{3}\right)$ and the $2 / 26$ collection $\left(2.4 \mathrm{M} \mathrm{m}^{3}\right)$ is almost certainly due to the higher humidity and deeper boundary-layer for the $2 / 19$ simulation. The boundary-layer is shallower on $2 / 26$ due to the earlier collection time. As noted in the discussion of the $2 / 19$ results, the simulated humidity is probably too high by about $0.5 \mathrm{~g} / \mathrm{kg}$. Based on the results here, correcting the humidity bias for the $2 / 19$ simulation would likely reduce the simulated plume volume by $30 \%$. For the current study, the reconstructed plume volume $\left(2.5 \mathrm{M} \mathrm{m}^{3}\right)$ agrees closely with the simulated volume for a tower friction of 6.5 . Since the reconstructed volume is an overestimate of the true plume volume, the best value of tower friction for this simulation is probably a little less than 6.5 . 


\section{WSRC-TR-99-00174}

\section{May 1999}

A set of camcorder images used for volume reconstruction is shown in Figure 22. The tower friction of 6.5 produced a tower exit air temperature of $308^{\circ} \mathrm{K}$ for the tower 2 plume simulation (see Table 2). The computed tower temperature for a friction of 2.0 was $303.3^{\circ} \mathrm{K}$. As noted above, temperature measurements at the drift eliminators in tower 2 indicated a temperature of $306^{\circ} \mathrm{K} .10$-minute average $\mathbb{R}$ temperatures were measured at each tower exit. The measured IR temperatures were $299.4^{\circ} \mathrm{K}$ and $298.0^{\circ} \mathrm{K}\left( \pm 0.6^{\circ} \mathrm{C}\right)$ for tower 1 and 2, respectively (see Table 2). As expected, these temperatures are substantially lower than the measured or simulated tower temperatures. However, the difference in measured $\mathbb{R}$ temperatures between towers 1 and $2\left(1.4^{\circ} \mathrm{C}\right)$ is exactly that predicted by the combined energy/momentum balances. The calculated maximum $\mathbb{R}$ temperatures, based on a several simulation times, were $301^{\circ}$ and $297^{\circ} \mathrm{K}( \pm$ $1.5^{\circ} \mathrm{K}$ ) for towers 1 and 2 respectively. While these values are in reasonable agreement with the measured IR temperatures, the $4^{\circ} \mathrm{K}$ difference is larger than expected. Typical frequency distributions of plume radiance for both radiation streams are shown in Figure 23.

\section{$3 / 04 / 98$}

Data were collected between 1300 and 1315 local time $(1800-1815 \mathrm{Z})$. Tower 2 was operating at about $80 \%$ of full power $(1865 \mathrm{MW})$. This was the lowest ambient temperature, lowest humidity and highest wind speed collection ( $9.5^{\circ} \mathrm{C}, 2.9 \mathrm{~g} / \mathrm{kg}, 6-7 \mathrm{~m} / \mathrm{s}$ at tower top). Medium Range Forecast model data at 12 $Z$ were used to initialize the RAMS simulation; the ETA data produced an unstable simulation. Vertical profiles of simulated temperature and humidity are compared with tower data in Figure 24 . The simulated temperatures are uniformly high by about $1^{\circ} \mathrm{K}$ between the ground and $300 \mathrm{~m}$ AGL. The simulated humidity near the surface was high by $10 \%$. These are relatively small errors and should produce some cancellation with respect to errors in the simulated cloud volume. Simulated cloud volumes for the combined plumes were $1.8 \times 10^{6} \mathrm{~m}^{3}$ and $1.5 \times 10^{6} \mathrm{~m}^{3}$ for tower frictions of 6.5 and 2.0 , respectively. In both cases, the tower 2 volume was about $50 \%$ of the tower 1 volume. This difference is in line with the results of previous plume sensitivity studies. The reconstructed cloud volume from imagery was $4.0 \times 10^{6}$ $\mathrm{m}^{3}$. A separation of tower 1 and 2 plume volumes was not possible from the imagery, although the tower 2 volume was clearly smaller. The difference between simulated and measured plume volumes is enormous compared to previous results. A qualitative comparison of images from this collection with those from the $2 / 19$ collection suggests that the reconstructed volume here should be larger than that obtained for $2 / 19$ (3.2 $x 10^{6} \mathrm{~m}^{3}$ ). On the other hand, the simulated volume (based on cloud water isosurfaces) seems to be smaller than that suggested by the imagery. Thus it appears that the simulated plume volume is in error, although the boundary-layer simulation seems reasonable based on other simulations. It should be noted that the plume images produced from the SRS location were of very poor quality during this collection. This problem and the obscuration of the tower tops due to plume downwash made the implementation of the volume reconstruction algorithm difficult. Thus it is certainly possible that the reconstructed volume estimate of $4.0 \times 10^{6} \mathrm{~m}^{3}$ is high. A set of images used in the volume reconstruction algorithm is shown in Figure 25.

The simulated plume temperature at the tower 1 exit was $306.3^{\circ} \mathrm{K}$ and $300.9^{\circ} \mathrm{K}$ for tower frictions of 6.5 and 2.0; simulated plume temperatures for tower 2 were $303.8^{\circ} \mathrm{K}$ and $298.8^{\circ} \mathrm{K}$. Measured internal tower temperatures at the drift eliminator of tower 1 indicated an average temperature of $303^{\circ} \mathrm{K}$. IR temperature measurements directly above the tower top yielded 10-minute average temperatures of $294.8^{\circ} \mathrm{K}$ and $292.5^{\circ}$ $\mathrm{K}\left( \pm 1^{\circ} \mathrm{K}\right)$ for towers 1 and 2 . As seen in the $2 / 19$ collection, the $\mathbb{R}$ plume temperature is considerably cooler than the internal tower temperature, but the IR temperature difference between the tower 1 and 2 plumes $\left(2.3^{\circ} \mathrm{K}\right)$ is in good agreement with the computed difference in tower temperatures from the energy and momentum balances. The calculated maximum IR temperatures based on the plume simulation were $295^{\circ} \mathrm{K}$ and $293^{\circ} \mathrm{K}\left( \pm 1.5^{\circ} \mathrm{K}\right)$. Thus measured and calculated $\mathrm{IR}$ temperatures are in good agreement. This is mildly surprising since the difference between the measured and simulated plume volumes is so large. An IR image from the Inframetrics 760 camera is shown in Figure 26. This image was taken from an upwind location approximately $1 \mathrm{~km}$ from the tower. The high wind velocity $(6-7 \mathrm{~m} / \mathrm{s})$ at the tower top produces the small plume profile and strong downwash in this image. The $20 \%$ power difference between the two towers is apparent in this image. Frequency distributions of measured plume radiances at two times are shown in Figure 27. The distribution at the top of Figure 27 is based on the plume images in Figure 26. 
WSRC-TR-99-00174

\section{May 1999}

Radiance frequency distributions for simulated plumes are shown in Figure 28. While there are similarities between the measured and calculated distributions, a direct comparison of radiance distributions from collected imagery with those calculated from plume simulations is unlikely to be an aid in determining power.

Data were collected between 1300 and 1315 local time. Only tower 1 was operating during this collection. Tower temperature data were collected at about $10 \mathrm{~m}$ above the drift eliminators. These data indicated an average temperature of $297^{\circ} \mathrm{K}$, with a spatial variability of $\pm 1^{\circ} \mathrm{K}$. The plume at this time was noticeably smaller than during previous collections. This observation was confirmed by a reconstructed plume volume of only $480,000 \mathrm{~m}^{3} \pm 73,000 \mathrm{~m}^{3}$ based on four image sets. Most of this uncertainty was produced by a high volume estimate from one of the four image sets used in the volume reconstruction. Excluding this high estimate, the reconstructed volume estimate becomes $438,000 \mathrm{~m}^{3} \pm 4,000 \mathrm{~m}^{3}$. The simulated plume volume for a tower friction of 6.5 was $360,000 \mathrm{~m}^{3} \pm 27,000 \mathrm{~m}^{3}, 18 \%$ smaller than the reconstructed plume volume based on 3 image sets. The small plume size appears to affect the $\mathbb{R}$ temperature measurements at the tower exit. A greater temporal variability was observed, with an apparent maximum $\mathbb{R}$ temperature of $302.9^{\circ} \mathrm{C}$ interrupted frequently with downward excursions to $299-300^{\circ} \mathrm{K}$. IR temperature data are shown in Figure 29. These data suggest a plume that is exhibiting significant variations in optical thickness at the tower exit. This conclusion is supported by radiative transfer computations for this simulation. The maximum absorption optical depth is only 1.4; maximum extinction optical depth is 2.2 . In Table 2 the median temperature from the 10-minute time series in Figure 26 is given as the measured $\mathbb{R}$ exit temperature $\left(302.3^{\circ} \mathrm{K}\right)$; the corresponding average temperature is $300.2^{\circ} \mathrm{K}$. The computed $\mathbb{R}$ temperature, based on the plume simulation with a tower friction of 6.5 , was $299^{\circ} \mathrm{K}$. The difference between the measured and computed $\mathbb{R}$ temperatures $\left(3^{\circ} \mathrm{K}\right)$ is considerably larger than seen in previous studies. Perhaps the small plume size is responsible for this difference. Frequency distributions of simulated plume radiance for both radiative stream directions is shown in Figure 30. Note that the minimum radiance for the W-E direction (view from space to ground at low elevation angle) is only 8.6 $\mathrm{W} / \mathrm{m}^{2}-\mathrm{sr}-\mu \mathrm{m}$; the ground radiance is $9.0 \mathrm{~W} / \mathrm{m}^{2}-\mathrm{sr}-\mu \mathrm{m}$. The corresponding result for the $2 / 19$ collection was $8.0 \mathrm{~W} / \mathrm{m}^{2}-\mathrm{sr}-\mu \mathrm{m}$ (see Figure 20 ). This is due to a higher plume rise on $2 / 19$ generating colder cloud temperatures aloft. The fact that plume radiance is responsible for both the hottest and coldest $\mathbb{R}$ temperatures in a scene is often observed in space-based imagery.

Tethersonde data were collected during this experiment, although they were not used in the initialization of the plume simulation. Only ETA model data and surface observations were used for initialization. A comparison of the tethersonde data with a vertical profile from the boundary-layer simulation is shown in Figure 31. The simulated temperature profile appears to be unbiased with respect to the tethersonde data with an error of about $\pm 1^{\circ} \mathrm{K}$. The simulated humidity above the tower $(>170 \mathrm{~m})$ is biased high by about $0.2 \mathrm{~g} / \mathrm{kg}(3 \%)$. While the overall simulation of the thermodynamic profile is in good agreement with the tethersonde data, it is clear that fine structure in the tethersonde data is not captured by the simulation.

\section{$04 / 02 / 98$}

Data were collected between 1145 and 1200 local time (1645 - 1700 Z). Only tower 1 was operating. Camcorder imagery suggested that the cloud water plume size at this time was similar to that seen during the $3 / 26$ collection. The ambient temperature was about $1^{\circ} \mathrm{C}$ higher than the $3 / 26$ collection, while the ambient humidity was $30 \%$ lower $(4.7 \mathrm{vs} 6.7 \mathrm{~g} / \mathrm{kg})$. These values are based on SRS tower data between 2 and $60 \mathrm{~m}$ AGL. Measurements at the Vogtle towers ( $1 \mathrm{~m} \mathrm{AGL)} \mathrm{indicated} \mathrm{a} \mathrm{humidity} \mathrm{of} 5.7 \mathrm{~g} / \mathrm{kg}$ at 1130 and $5.0 \mathrm{~g} / \mathrm{kg}$ at 1200 local time. The SRS tower data also indicated a rapid change in humidity prior to 1200 local time. Tethersonde data were collected at SRS, but were not used in the initialization of the plume simulation. These data, along with simulated profiles, are shown in Figure 32; agreement is quite good. Computed tower temperature and tower exit velocity for the plume simulation were almost identical to those for the $3 / 26$ simulations. Thus the dryer atmosphere above the cooling tower during the $4 / 2$ collection (relative to the $3 / 26$ collection) should result in a smaller plume. A comparison of simulated plume volumes (see Table 2) supports this: $360,000 \mathrm{~m}^{3} \pm 27,000 \mathrm{~m}^{3}$ on $3 / 26$ versus $300,000 \mathrm{~m}^{3} \pm 30,000 \mathrm{~m}^{3}$ on 


\section{May 1999}

4/2. These results are for a tower friction of 6.5. Surprisingly, the reconstructed plume volume for the $4 / 2 / 98$ collection was slightly larger than the $3 / 26$ volume $\left(507,000 \mathrm{~m}^{3} \pm 50,000 \mathrm{~m}^{3}\right.$ vs $480,000 \mathrm{~m}^{3} \pm$ $73,000 \mathrm{~m}^{3}$ ). Thus the simulated plume volume is $41 \%$ smaller than the reconstructed plume volume, a relatively large error based on previous collections.

IR temperature data indicated a 10-minute average plume temperature of $302^{\circ} \mathrm{K}$ at the tower exit; the corresponding $\mathbb{R}$ temperature on $3 / 26$ was $302.3^{\circ} \mathrm{K}$. Plume radiation calculations at $10 \mu \mathrm{m}$ based on the plume simulations yielded a maximum $\mathbb{R}$ temperature of $299^{\circ} \mathrm{K}$. This is the same as the $3 / 26 \mathbb{R}$ temperature even though the simulated plume volume is $16 \%$ smaller. The difference between simulated and measured $\mathbb{R}$ temperatures is similar to that found for the $3 / 26$ collection $\left(3^{\circ} \mathrm{C}\right)$. Temperature data were collected in the tower at an elevation of approximately $30 \mathrm{~m}$ above the drift eliminators. A transect at this level between the wall and the tower center yielded an average temperature of $308^{\circ} \mathrm{K}$. The simulated tower exit temperatures were $311.3^{\circ} \mathrm{K}$ and $306.7^{\circ} \mathrm{K}$ for tower frictions of 6.5 and 2.0.

\section{Conclusions}

(1) Cooling tower plume simulations generated with a high-resolution, 3-D mesoscale atmospheric model can be a useful aid in power estimation. However, the plume must be large (computational limitation due to spatial resolution) with a reasonably stable geometry (steady atmospheric conditions; low to moderate winds). 3-D plume simulations are not likely to a practical resource for small, mechanical draft cooling towers, i.e. small generating facilities. Average plume cloud water volume and tower exit temperature (with supporting radiative transfer calculation) can be extracted from the plume simulations.

(2) Multiple plume simulations (6-10) will be required for a power estimate based on plume volume estimation. These simulations are needed to approximate lines of constant plume volume for specified ambient meteorological conditions.

(3) High-resolution, 3-D plume simulations are very sensitive to atmospheric conditions. A series of collections and supporting simulations will have to be performed to minimize the uncertainty inherent in meteorological data.

(4) Measured IR plume temperatures near the tower exit (ground-based) generally agree with the maximum temperatures derived from plume simulations and plume radiance calculations. The agreement between calculated and measured $\mathbb{R}$ temperatures degrades as the plume size decreases; calculated temperatures are biased low relative to the measured temperatures.

(5) Plume volume estimation based on imagery can be accomplished with 3 widely spaced view angles, although some overestimation will occur. Volume estimation will be difficult with only two view angles (MTI) since the overestimation problem will be exacerbated. Use of the solar shadow should be helpful in this regard. The separation in view angles for MTI will probably be far from optimal and this will increase the plume volume error. In addition, if the plume geometry is not sufficiently stable, large volume errors can occur due to the time gap between MTI looks (approximately 2 minutes). .

\section{References}

Nicholls, M.E., R.A. Pielke and R. Merony, 1993: "Large eddy simulation of microburst winds flowing around a building", J. of Wind Eng. and Ind. Aero., 46 \& 47, 229.

O'Steen, B.L., 1995: "Cooling tower simulation with a mesoscale model", SRTC Technical Report, SRTC557-96-01. 


\section{WSRC-TR-99'-00174}

\section{May 1999}

Stauffer, D.R. and N.L. Seaman,1990: "Use of four-dimensional data assimilation in a limited area mesoscale model. Part I: Experiments with synoptic-scale data", Mon. Wea. Rev., 118, 1250-1277.

Tripoli, G.J. and W.R. Cotton, 1982: "The Colorado State University three-dimensional cloud/mesoscale model - 1982. Part I: General theoretical framework and sensitivity experiments", J. Rech. Atmos., 16, 185-192. 


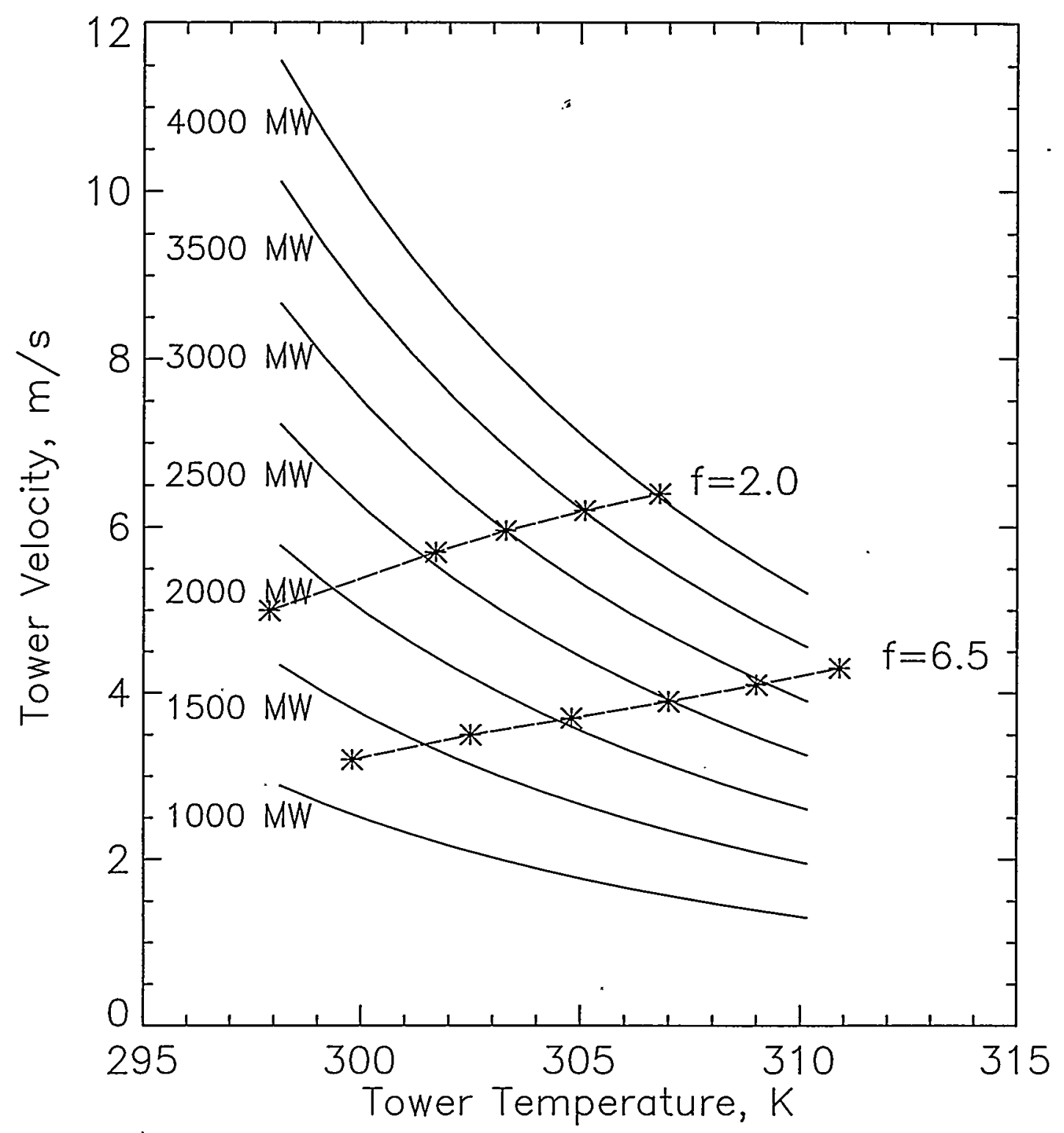

Figure 1. Solution of energy balance $(-)$ and momentum balance (-----) for overall tower friction coefficients of 2.0 and 6.5. Inlet wet bulb is $9^{\circ} \mathrm{C}$. 
WSRC-TR-99-00174

May 1999

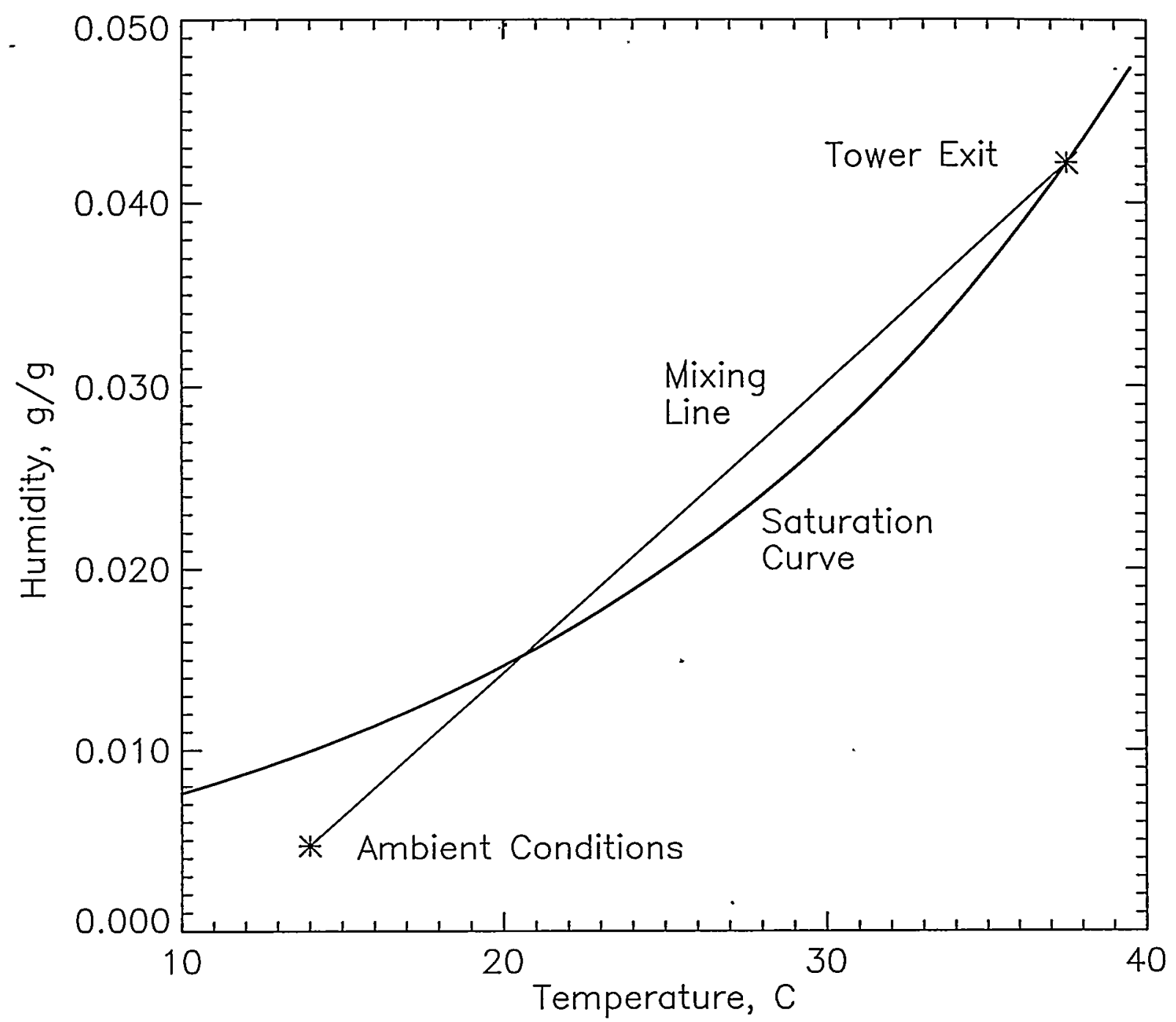

Figure 2. Psychrometric chart for a cooling tower operating in a vertically homogeneous atmosphere. 


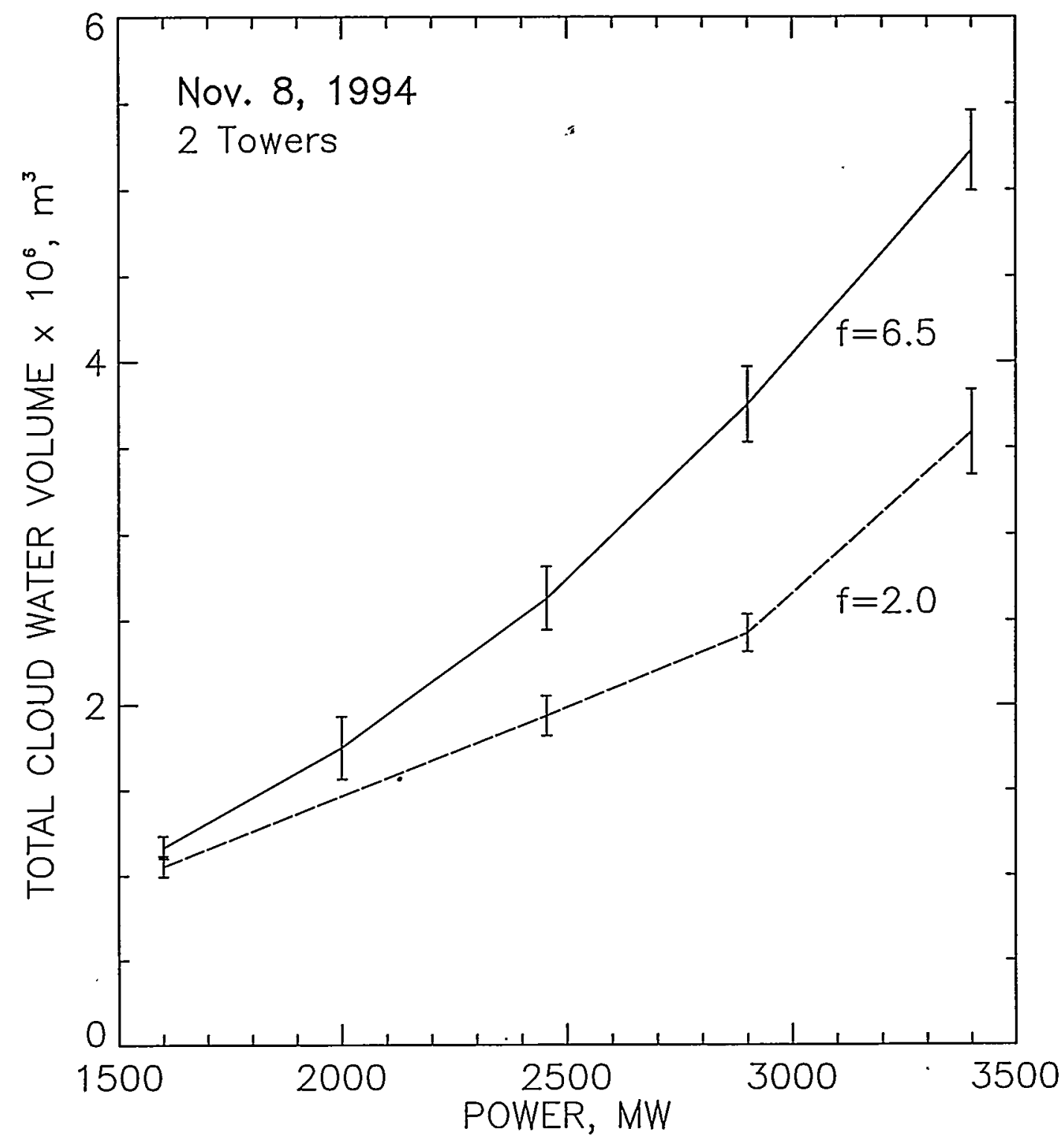

Figure 3. Cloud water plume volume, based on RAMS simulations, as a function of power for overall tower friction coefficients of 2.0 (low temperature, high velocity exit air) and 6.5 (high temperature, low velocity exit air). 


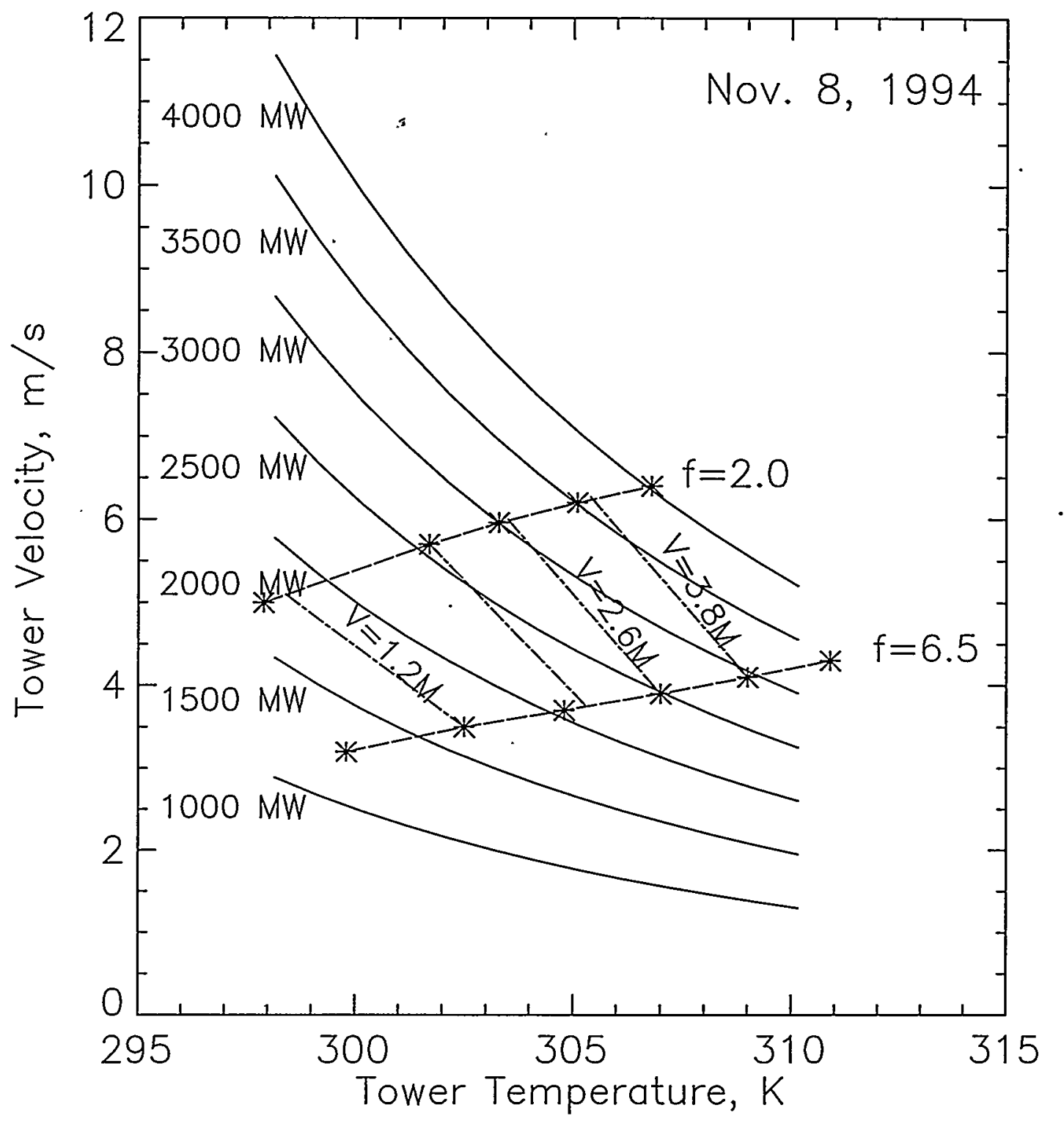

Figure 4. Lines of constant cloud water plume volume superimposed on results from Figure 1. 


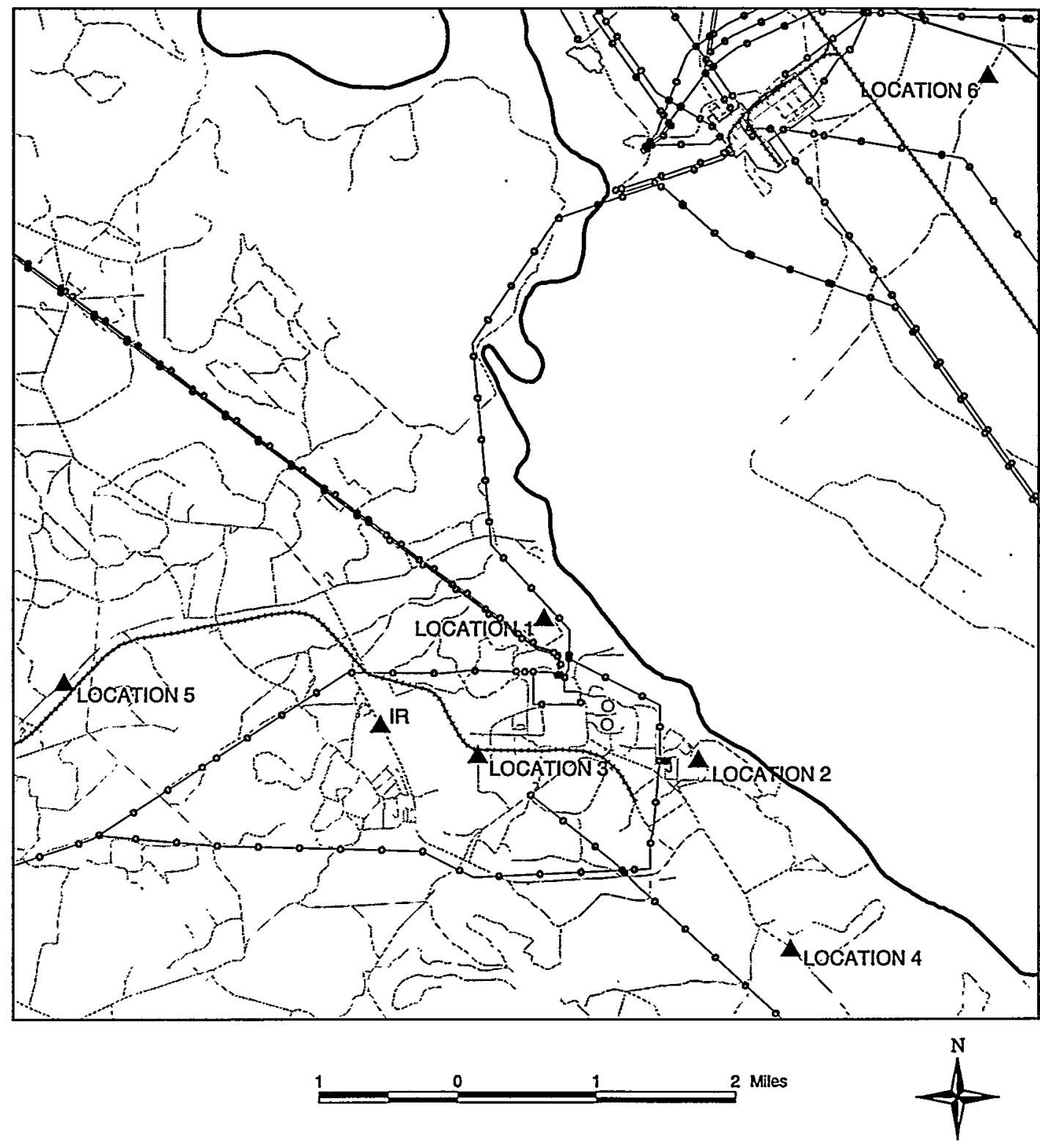

Figure 5. Map of Plant Vogtle area with cooling towers and observation locations indicated. 
WSRC-TR-99-00174

May 1999
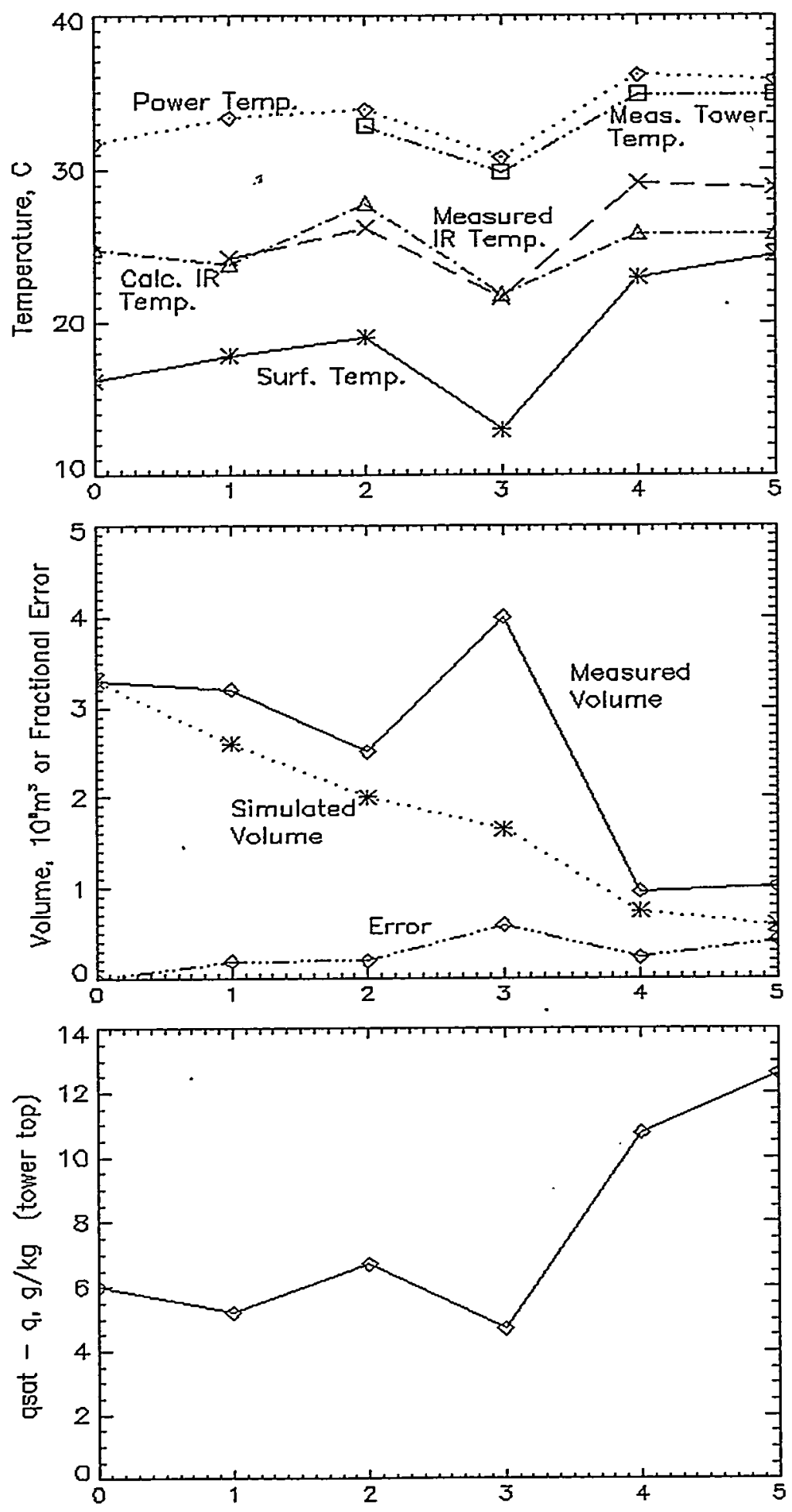

Figure 6. Temperature data, measured and calculated plume volumes, ambient air saturation deficits at tower top. Abscissa represents the 6 collection dates $(12 / 18,2 / 19,2 / 26,3 / 4,3 / 26,4 / 2)$. 

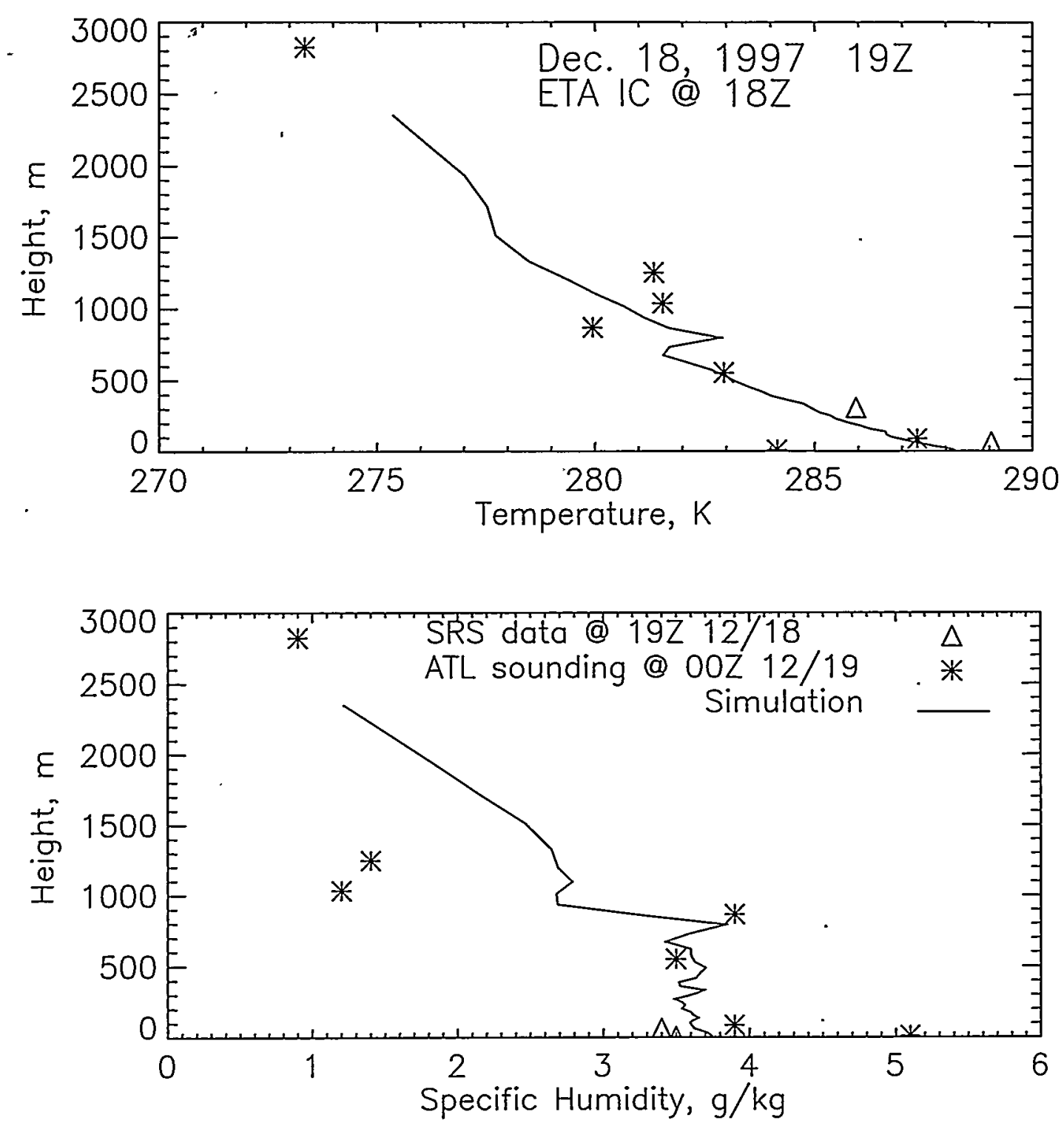

Figure 7. Vertical profiles of temperature and humidity from RAMS simulation, rawinsonde data and SRS tower data. 


\section{WSRC-TR-99-00174}

\section{May 1999}

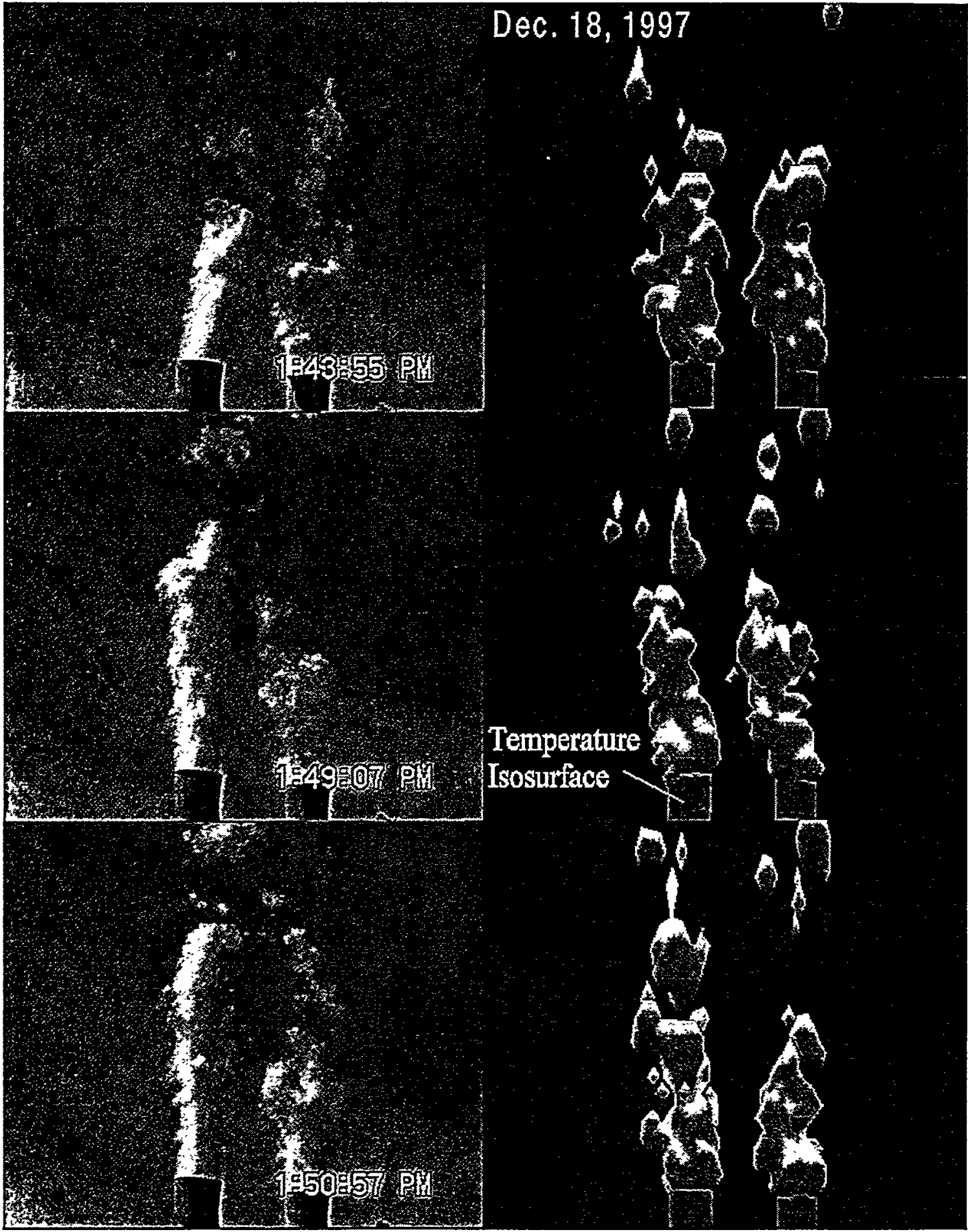

Figure 8. Camcorder images and simulated plumes for 12/18/97 collection. Temperature isosurface is at the tower exit air temperature. 
WSRC-TR-99-00174

May 1999

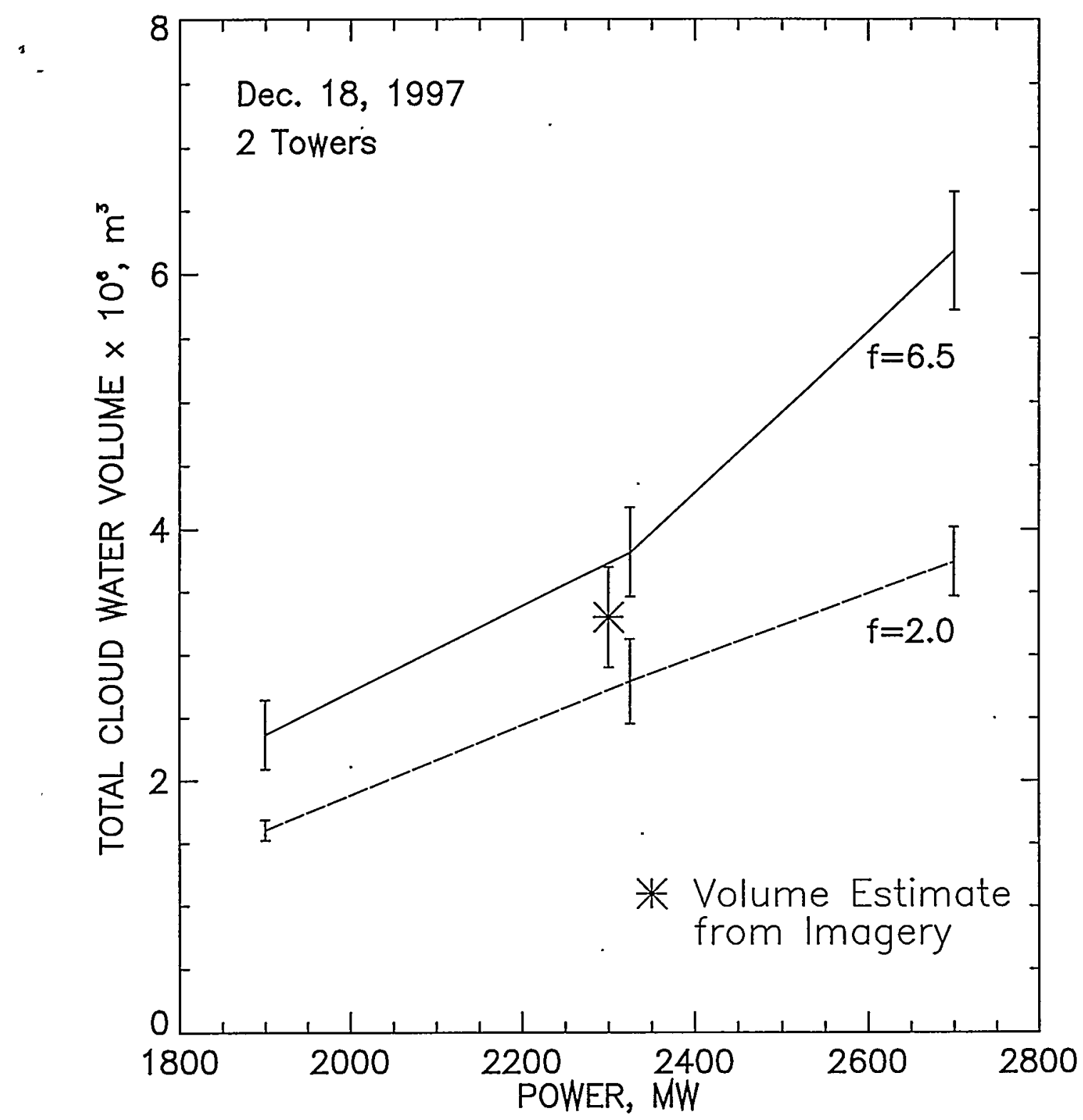

Figure 9. Calculated cloud water volume from plume simulations at 3 power levels and 2 tower friction coefficients. Volume estimate from camcorder images is also indicated. 
WSRC-TR-99-00174

May 1999

- Dec. 18, 1997

\section{2-Streom}

$2325 \mathrm{MW}$

$\mathrm{f}=6,5$
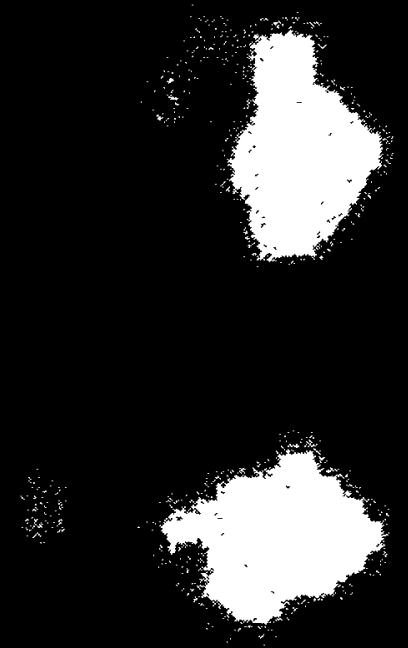

\section{Nadir Radiance at $10 \mu \mathrm{m}$}

Image Scaled Between 0 and $9 \mathrm{~W} / \mathrm{m}^{2}-\mathrm{sr}-\mu \mathrm{m}$

Figure 10. Nadir view of radiance based on cloud water plume simulation, Mie theory and 2-stream radiative transfer. No background radiance is included. 
WSRC-TR-99-00174

May 1999

Dec. 18, 1997

2-Stream

$$
\begin{aligned}
& 2325 \mathrm{MW} \\
& f=6.5
\end{aligned}
$$

\section{Degree Projection of $10 \mu \mathrm{m}$ Radiance}

$$
\text { Image Scoled Between } 0 \text { and } 9 \mathrm{~W} / \mathrm{m}^{2}-5 r-\mu \mathrm{m}
$$

Figure $11.90^{\circ}$ off-nadir view of radiance based on cloud water plume simulation, Mie theory and 2-stream radiative transfer. No background radiance is included. 
WSRC-TR-99-00174

May 1999

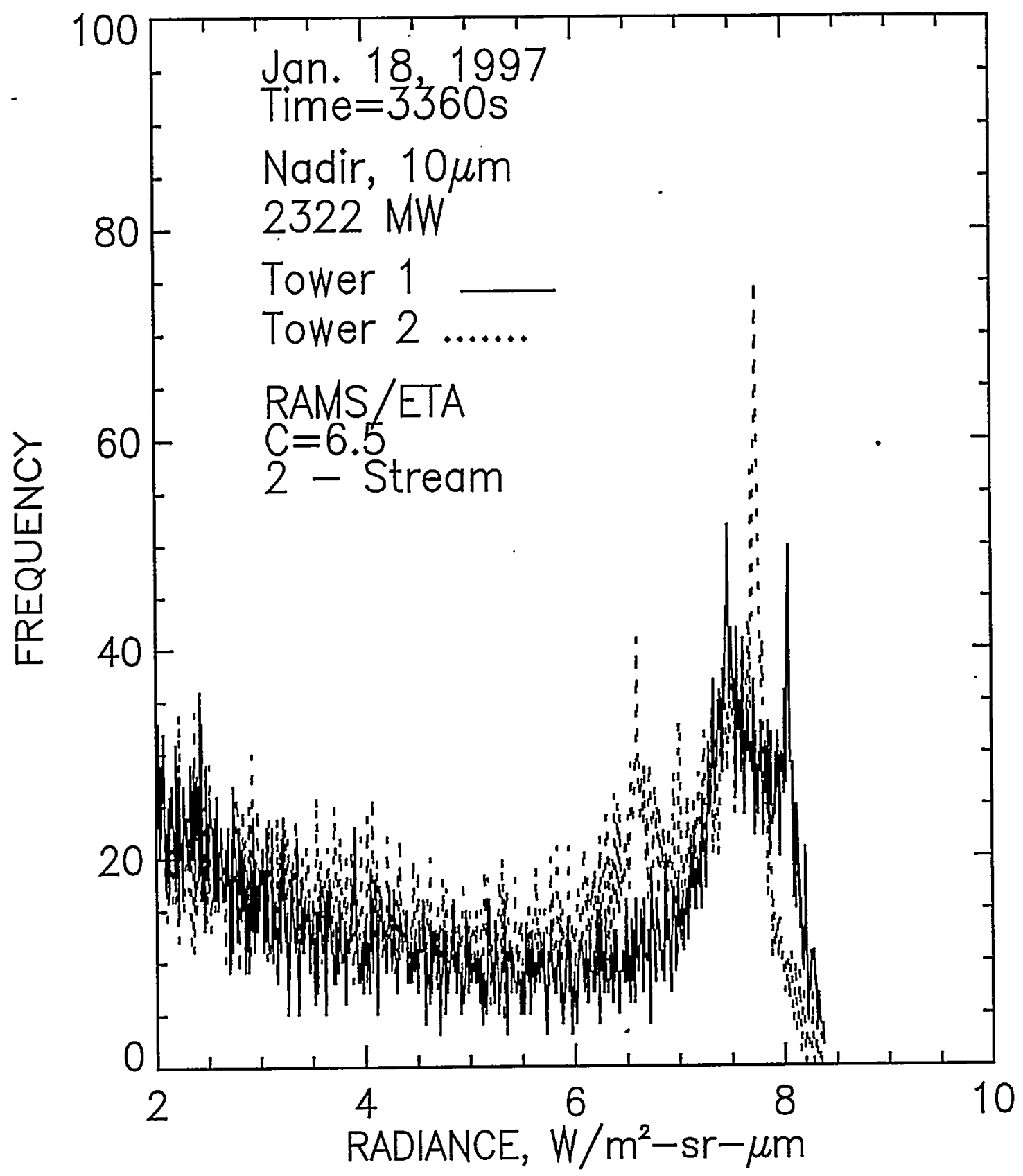

Figure 12. Frequency distribution of plume radiance from image in Figure 10. 


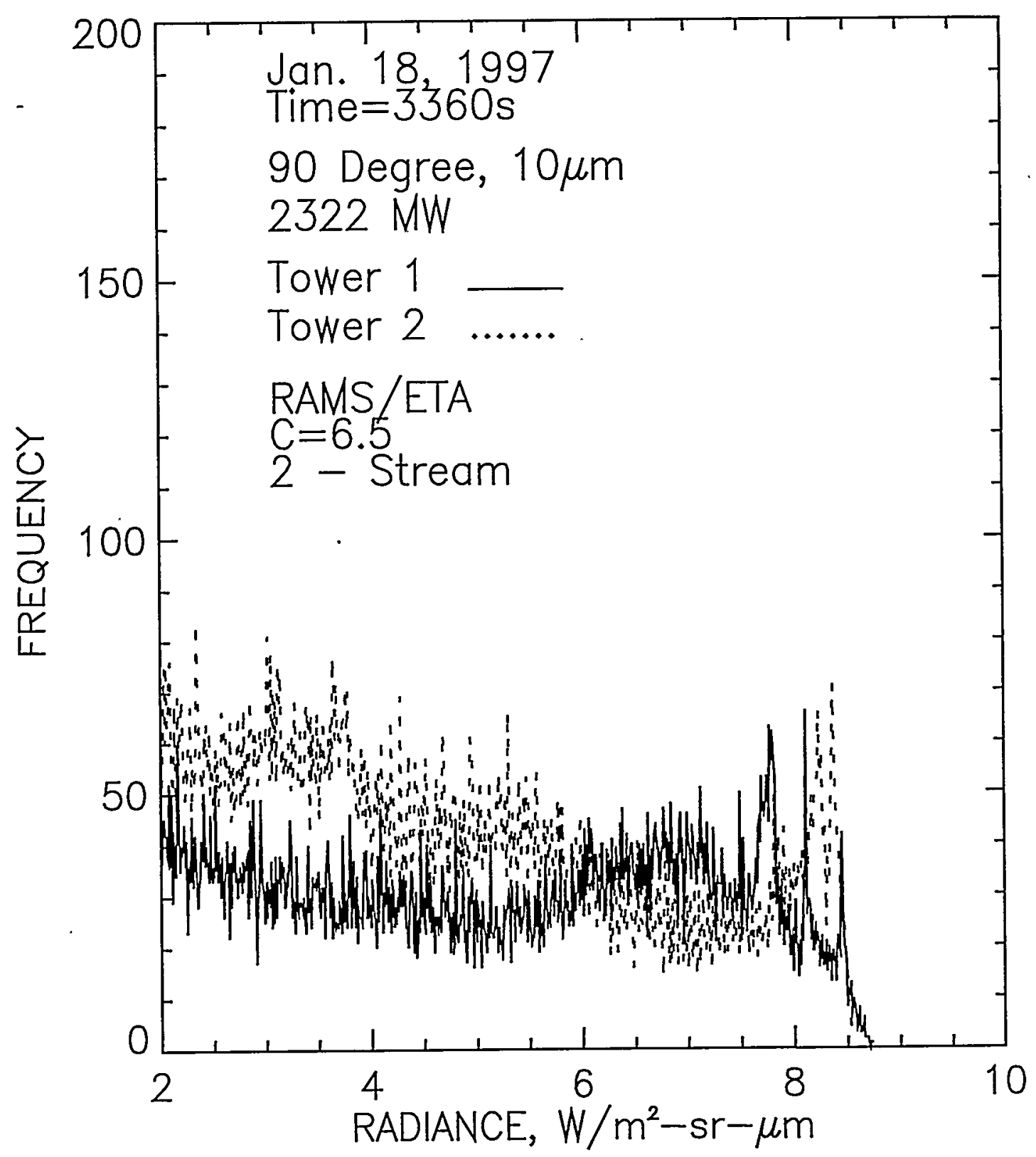

Figure 13. Frequency distribution of plume radiance from image in Figure 11. 

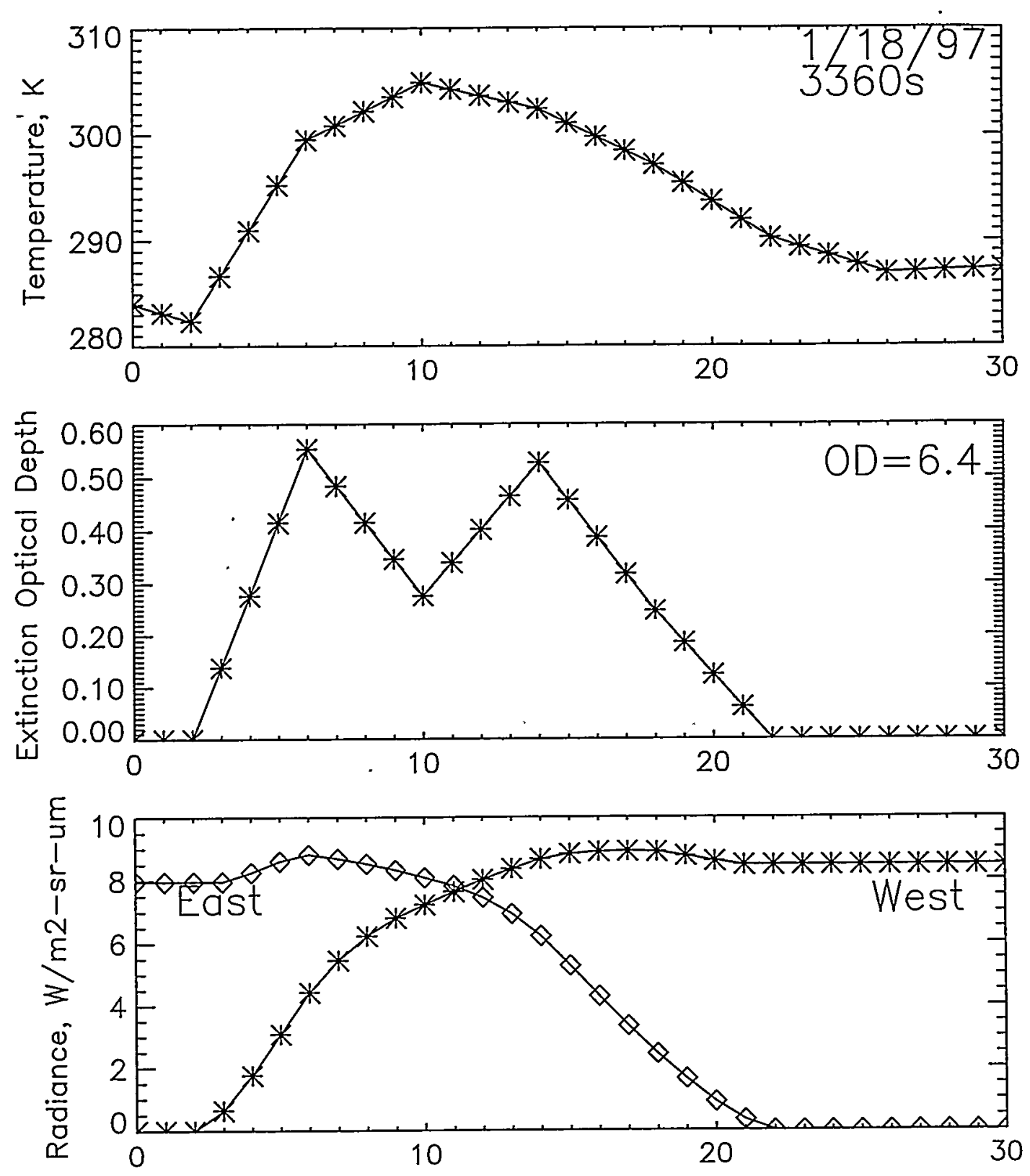

Figure 14. Temperature, extinction optical depth and radiance (both directions) along a typical radiative computational path parallel to the ground and just above the tower exit. Total extinction optical depth is 6.4 . 
May 1999

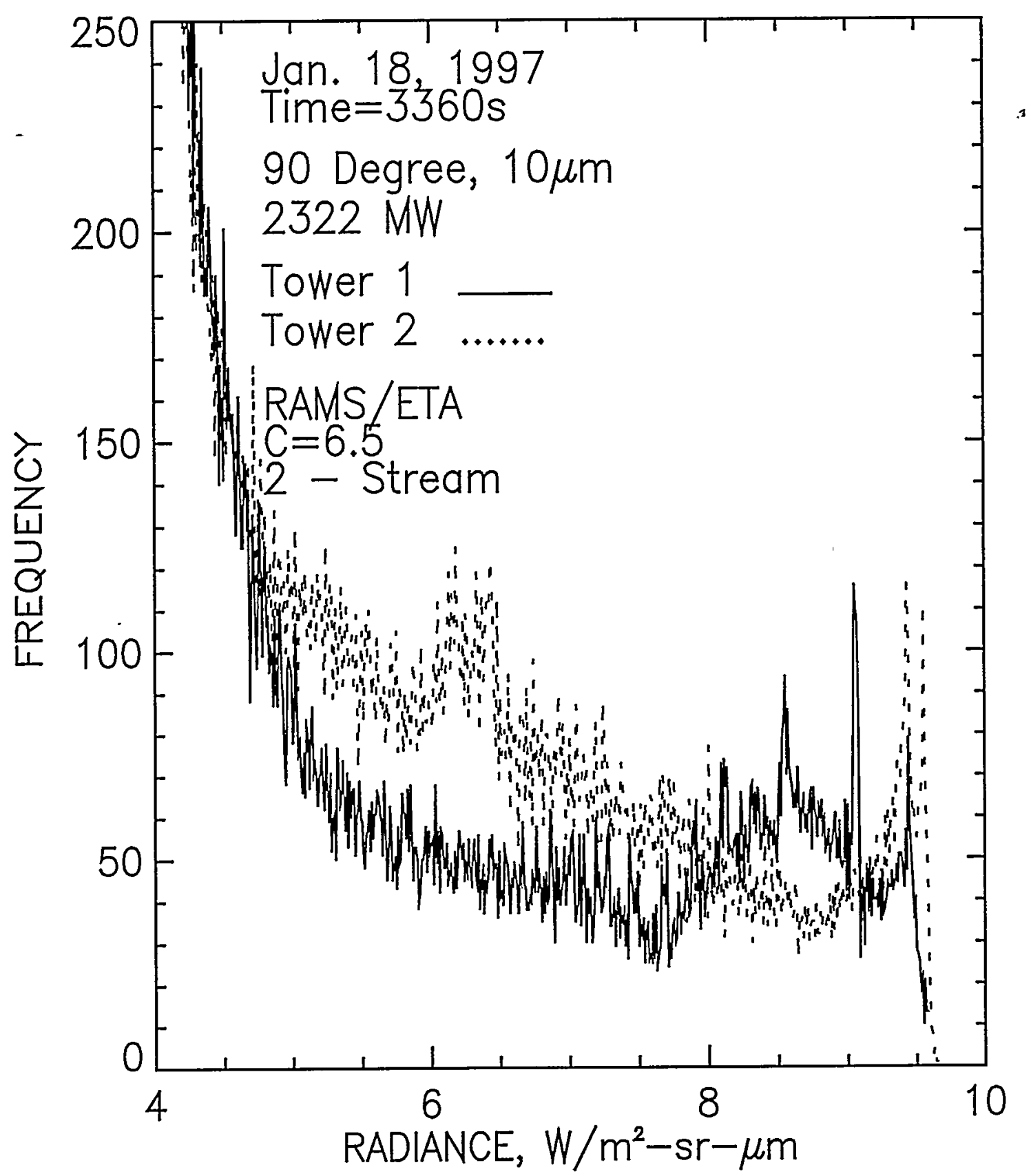

Figure 15. Same as Figure 13, but with background radiances of 4.0 (clear sky) and 9.0 (ground). 

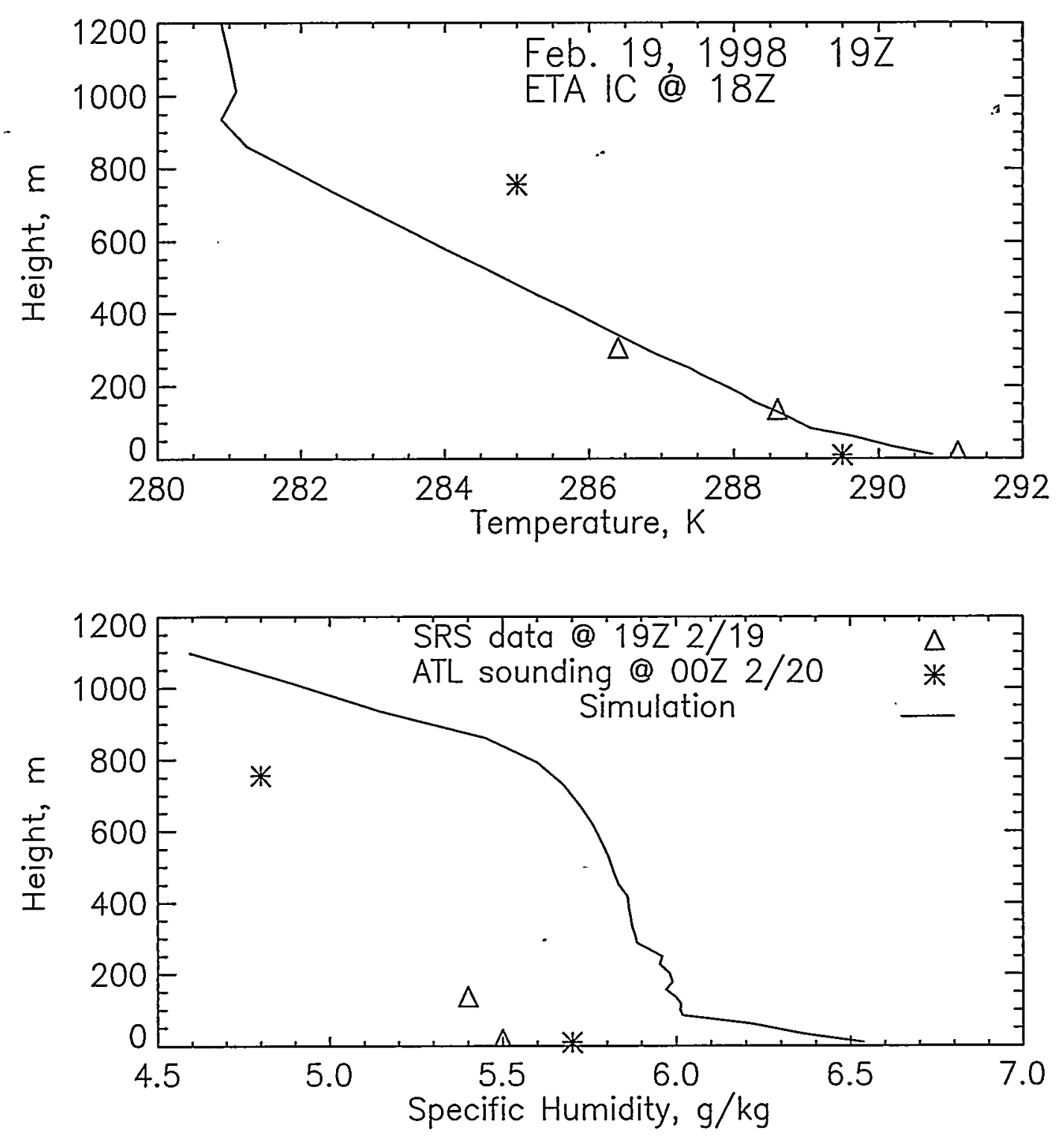

Figure 16. Vertical profiles of temperature and humidity from RAMS simulation, rawinsonde data and SRS tower data. 


\section{WSRC-TR-99̊-00174}

May 1999
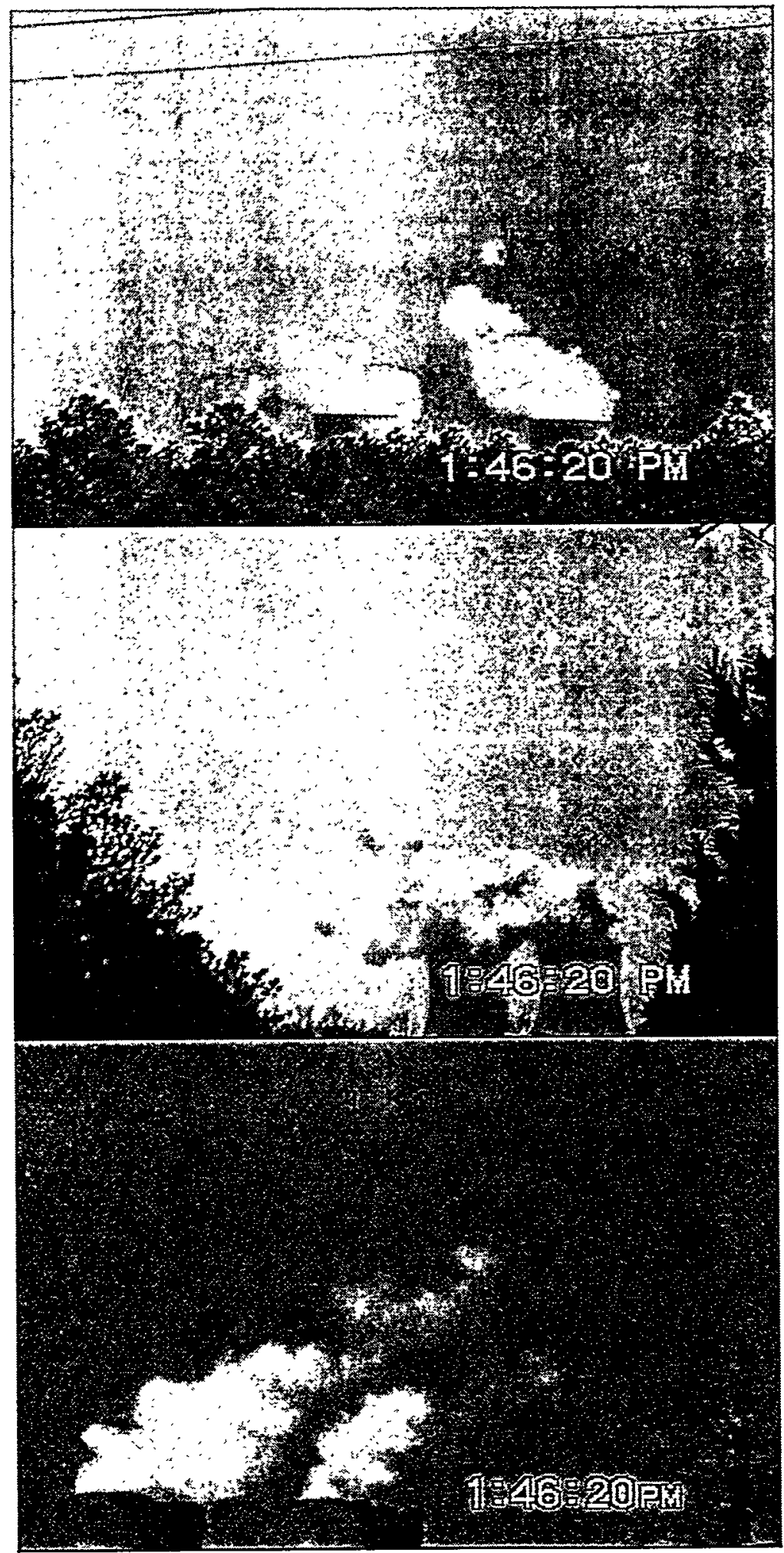

Figure 17. Camcorder images of cooling tower plumes on 2/19/98. 


\section{WSRC-TR-99-00174}

\section{May 1999}

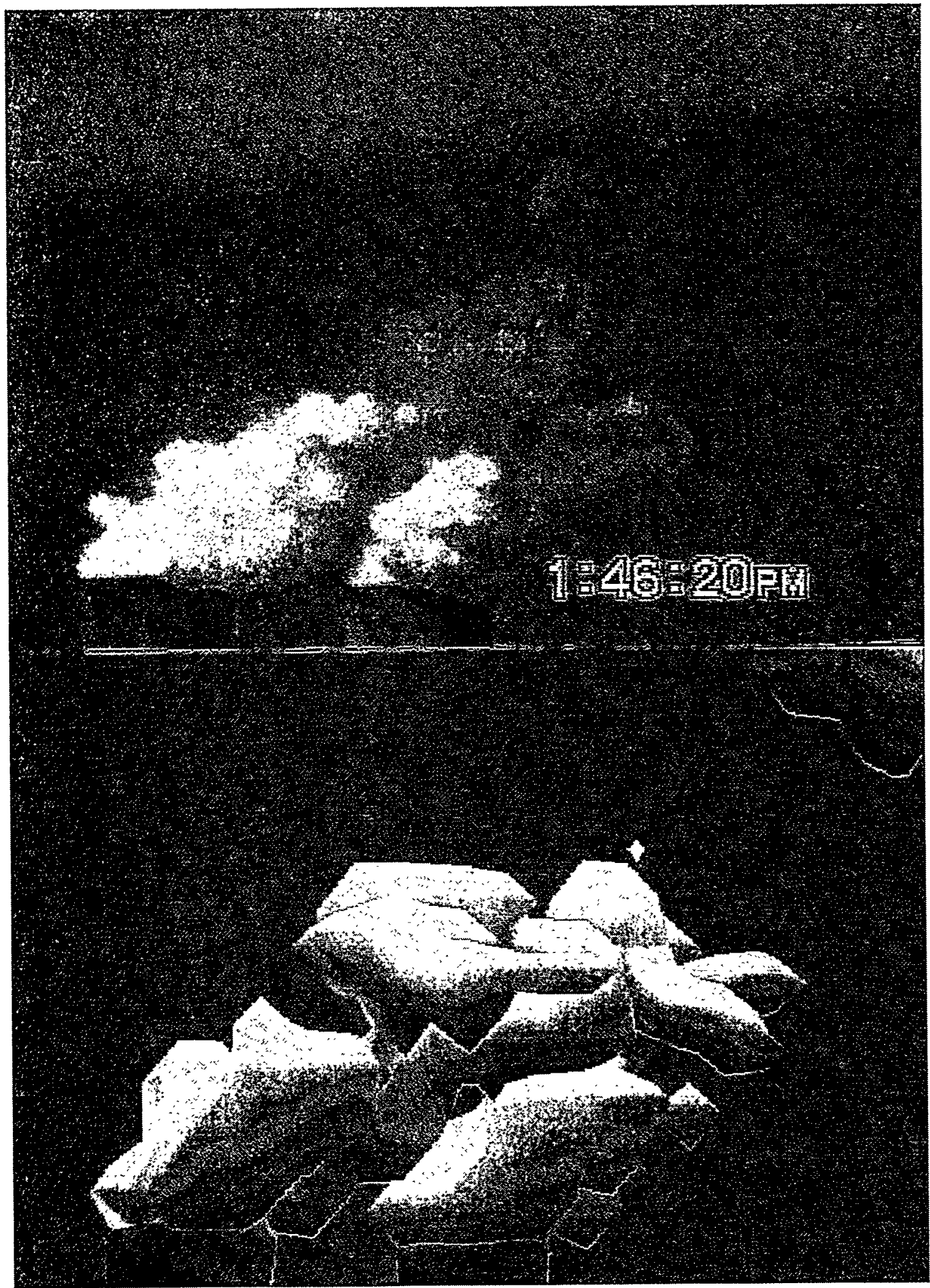

Figure 18. Simulated and observed plumes for 2/19/98 collection. 
WSRC-TR-99-00174

May 1999

Radiant Temperature of Cooling Towers

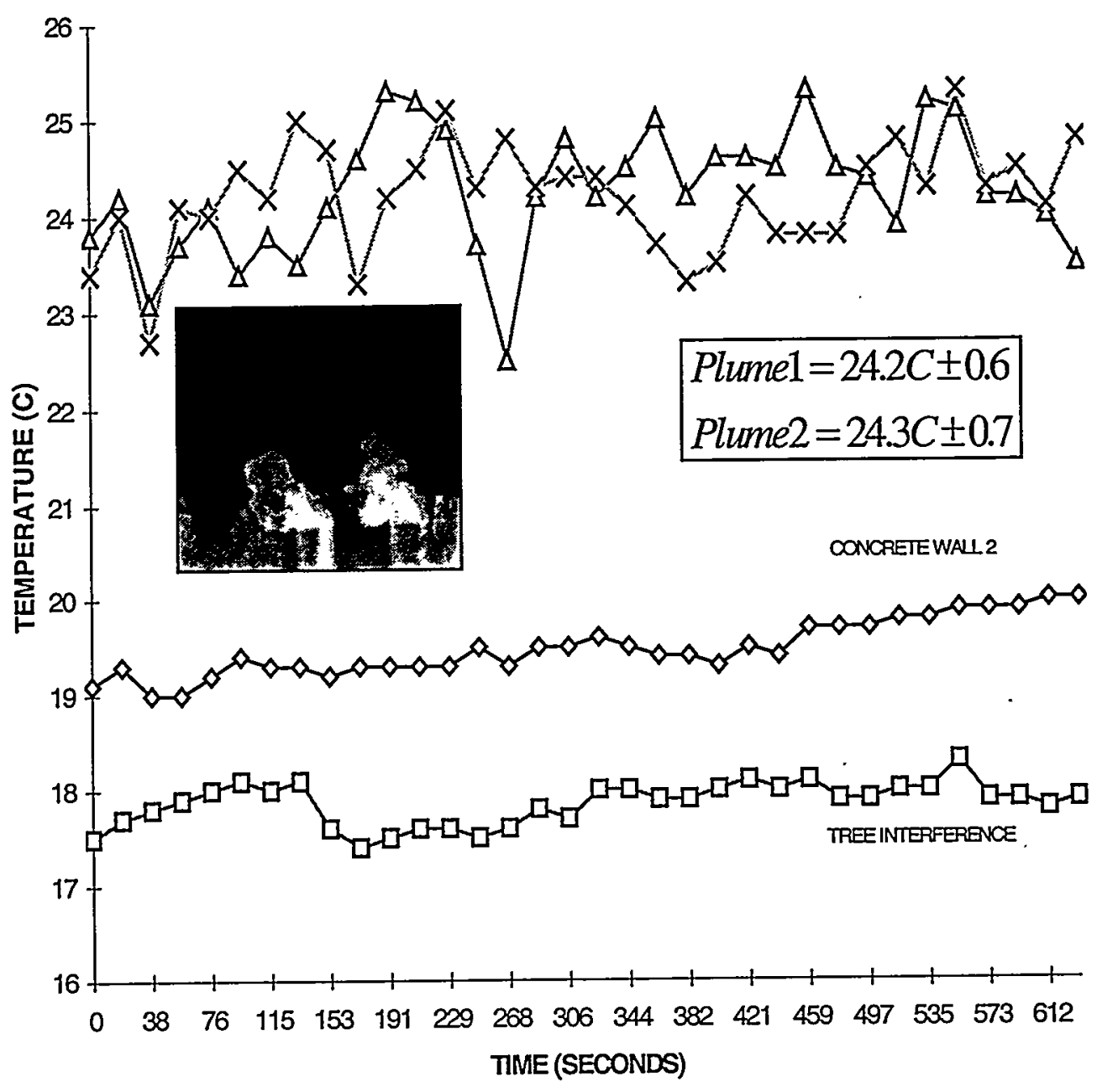

Figure 19. Radiant temperatures as measured by Inframetrics camera $(8-12 \mu \mathrm{m})$ at a point just above the each tower top. Insert is a typical IR image of the plumes 


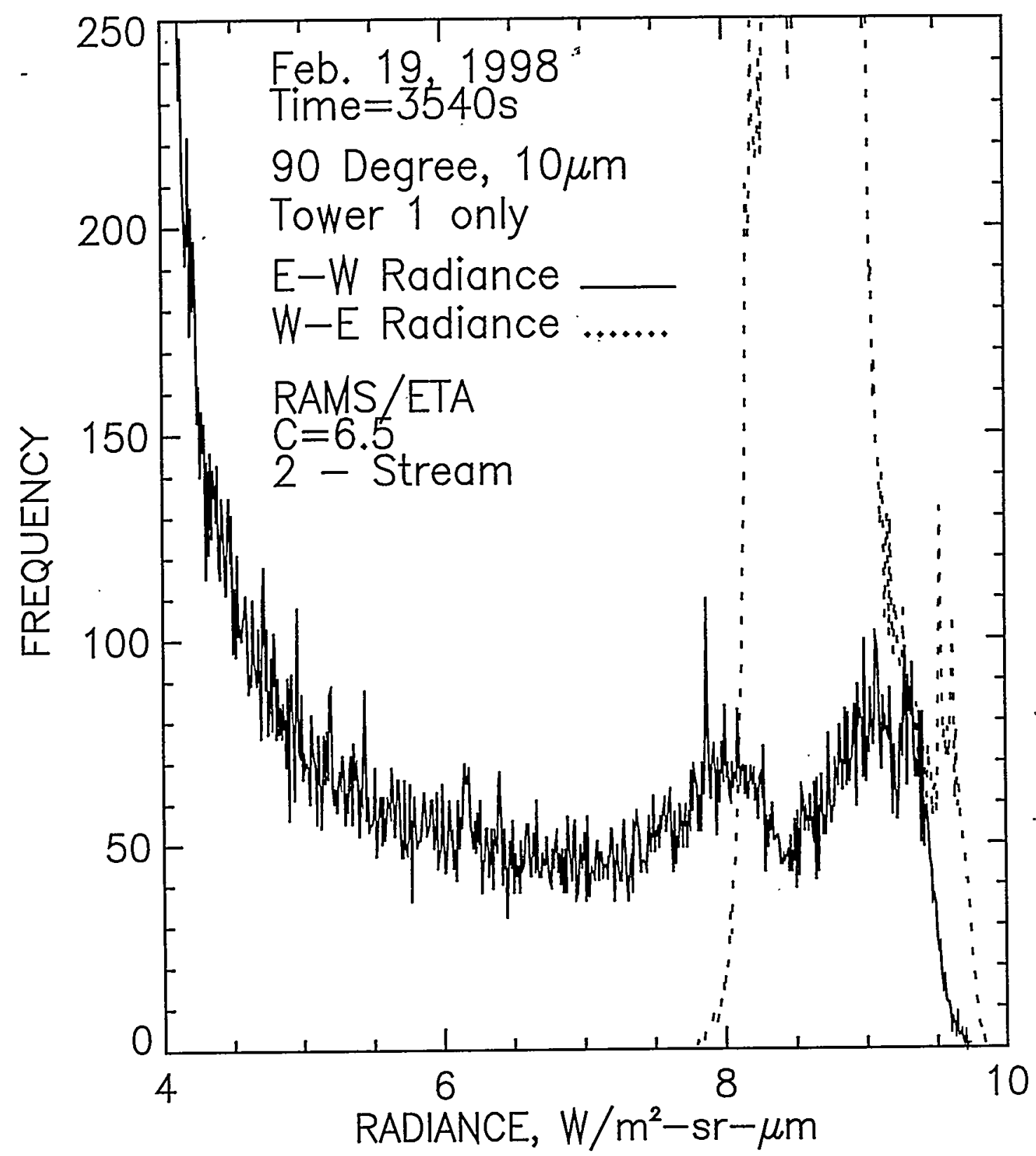

Figure 20. Radiance frequency distribution of a simulated plume image for both radiation stream directions. Background radiances are 4.0 (clear sky) and 9.0 (ground). 
WSRC-TR-99-00174

May 1999
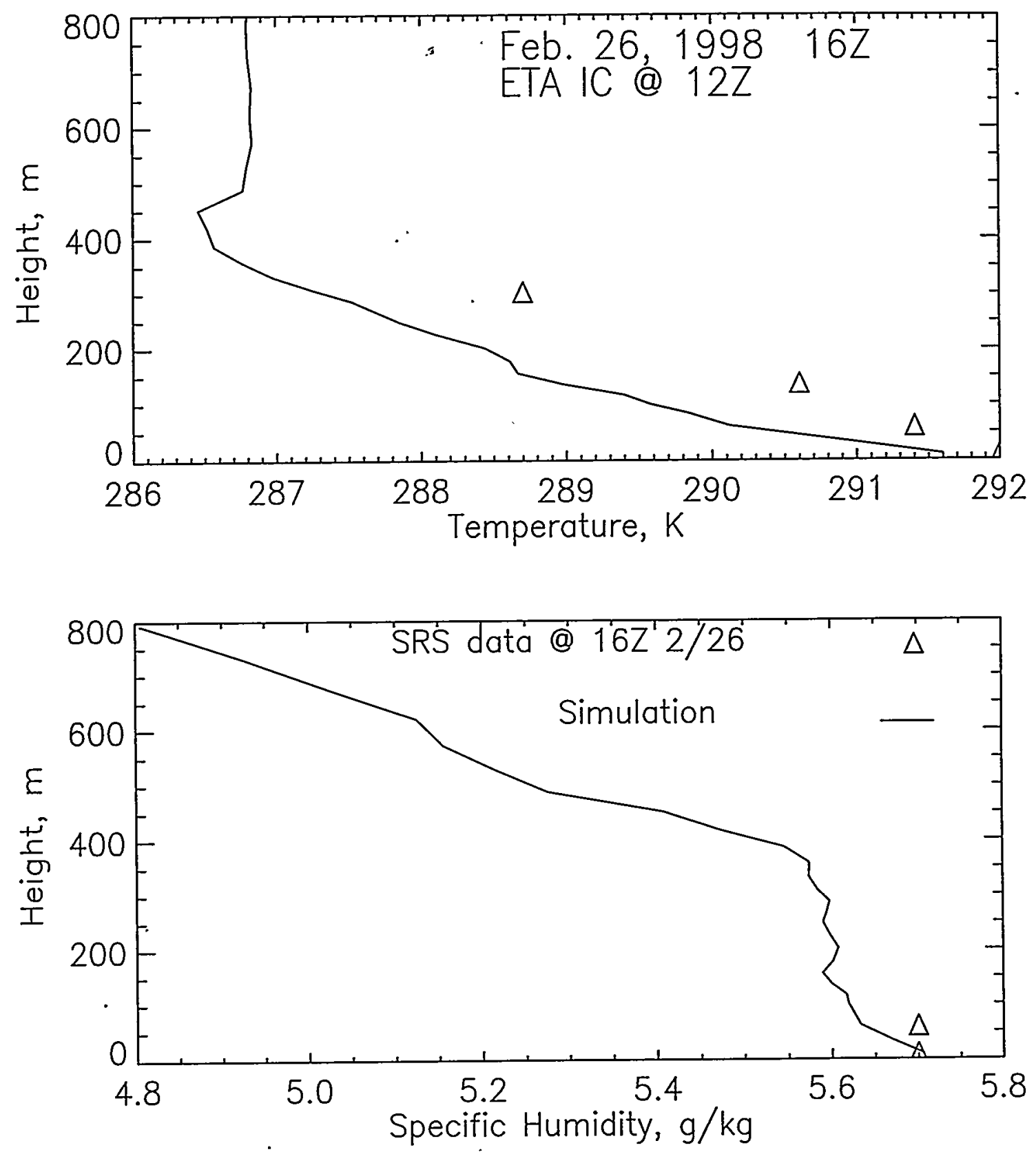

Figure 21. Vertical profiles of temperature and humidity from RAMS simulation and SRS tower data. 
WSRC-TR-99ी-00174

May 1999
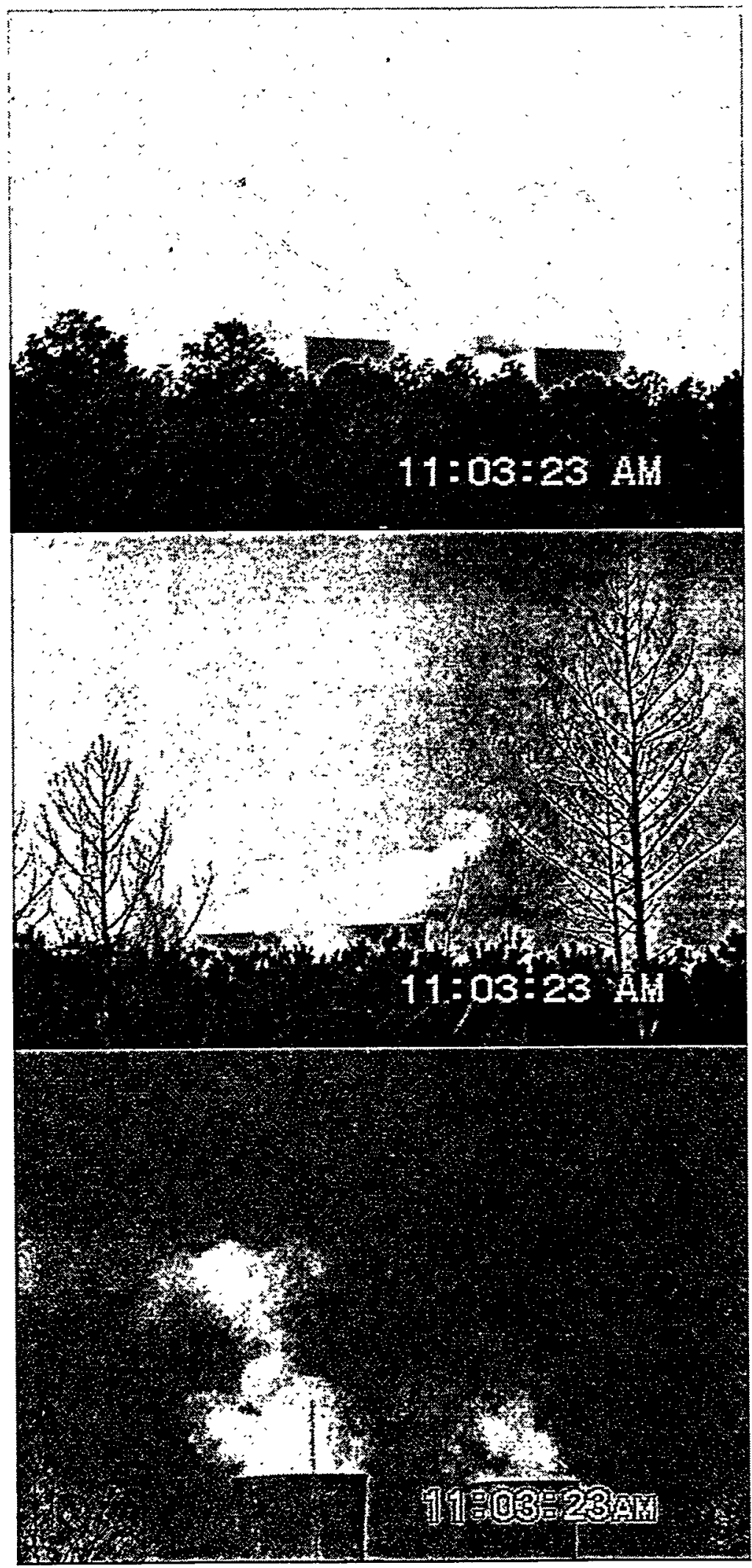

Figure 22. Camcorder images of cooling tower plumes on 2/26/98. 


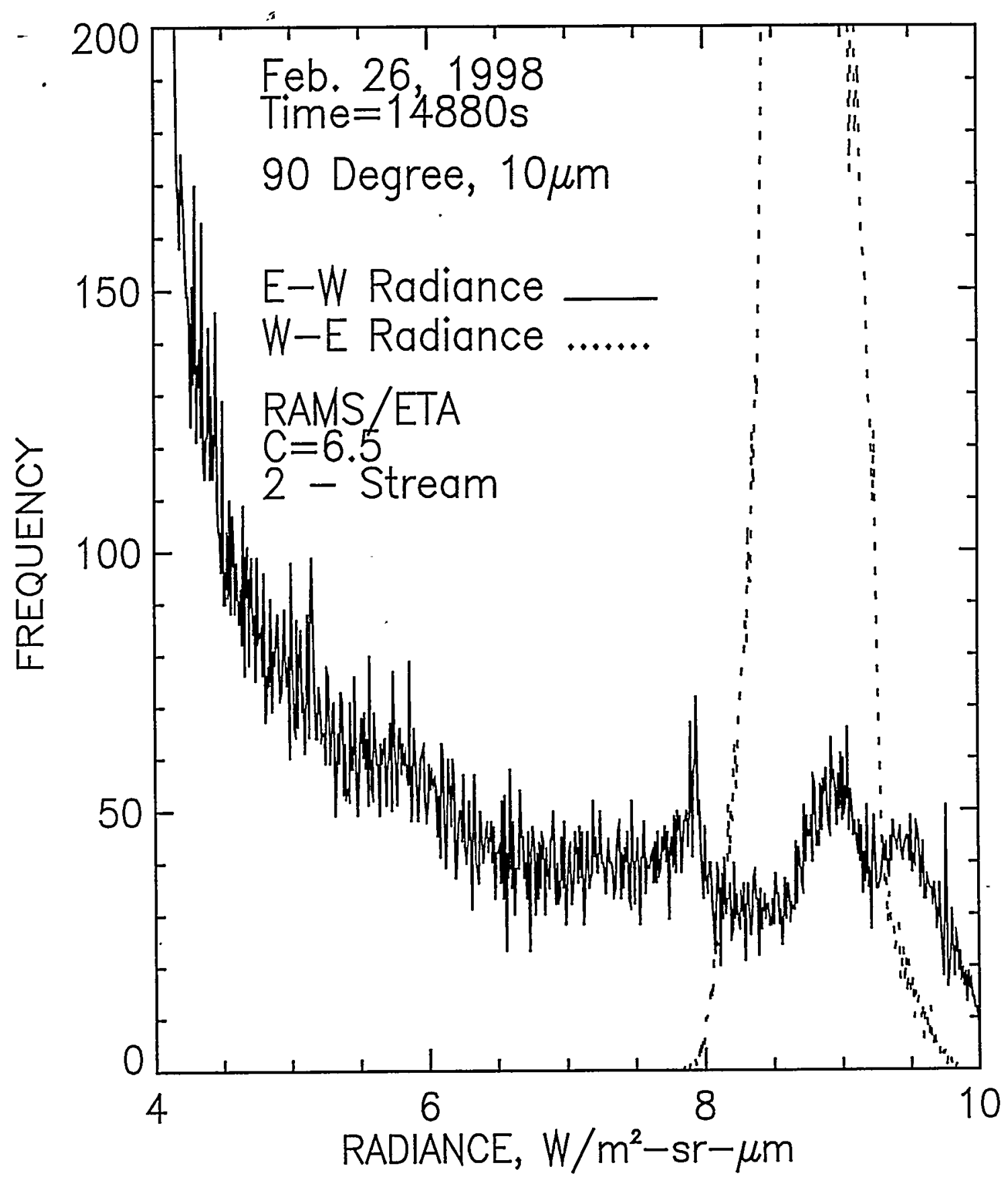

Figure 23. Radiance frequency distribution of a simulated plume image for both radiation stream directions. Background radiances are 4.0 (clear sky) and 9.0 (ground). 
May 1999
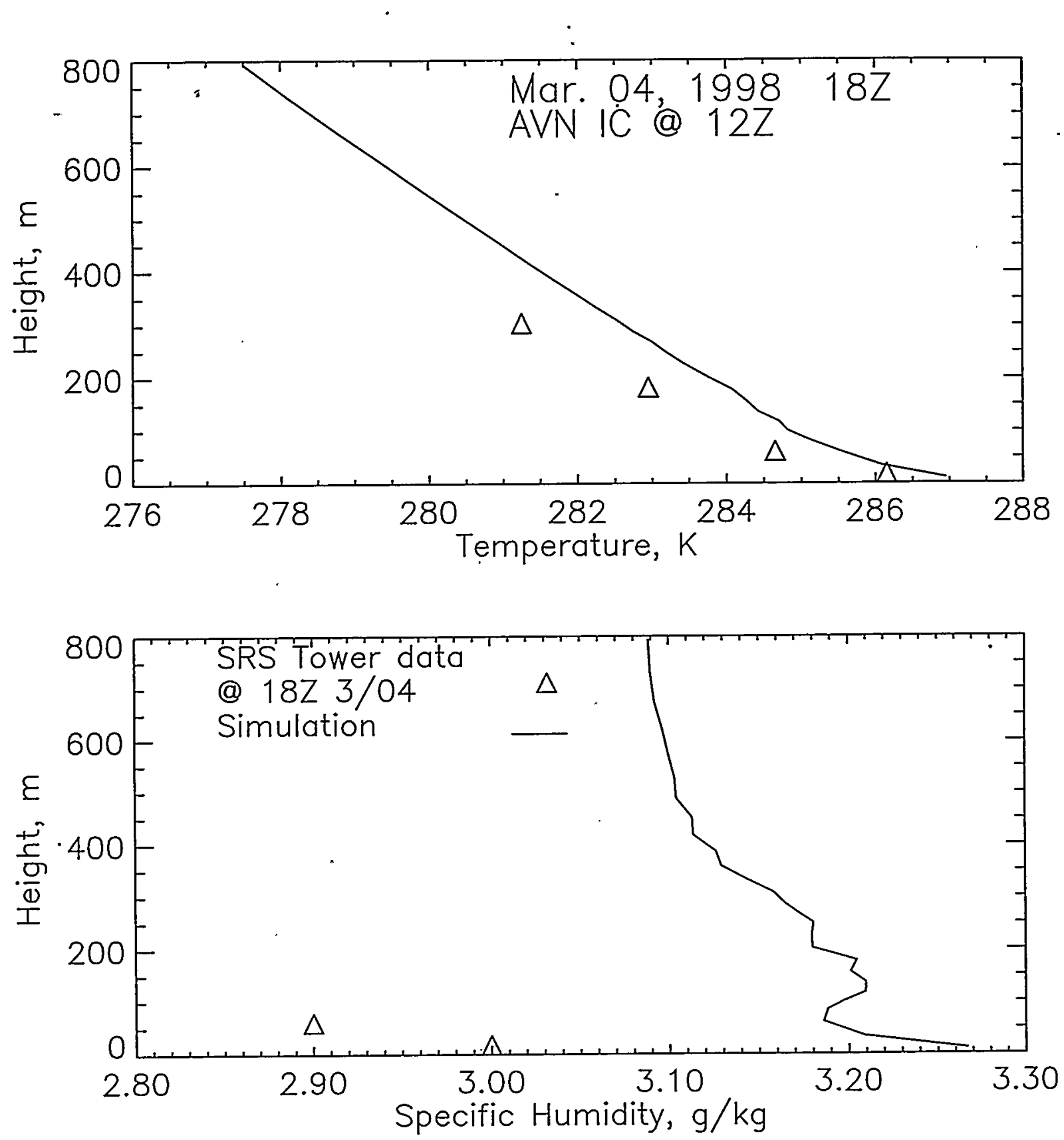

Figure 24. Vertical profiles of temperature and humidity from RAMS simulation and SRS tower data. 
WSRC-TR-99-00174

May 1999
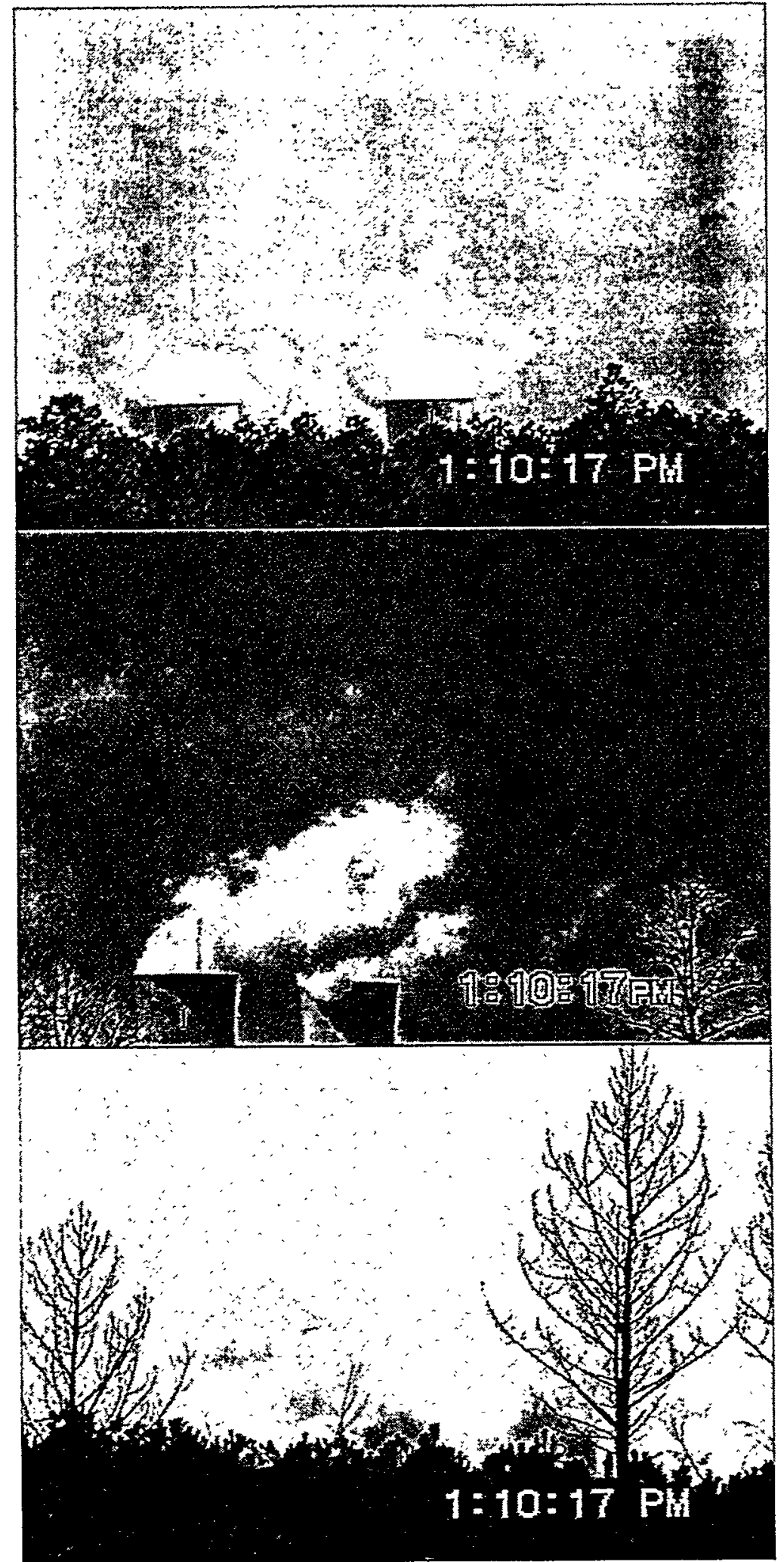

Figure 25. Camcorder images for volume reconstruction on 3/04/98. 


\section{WSRC-TR-99-00174}

May 1999

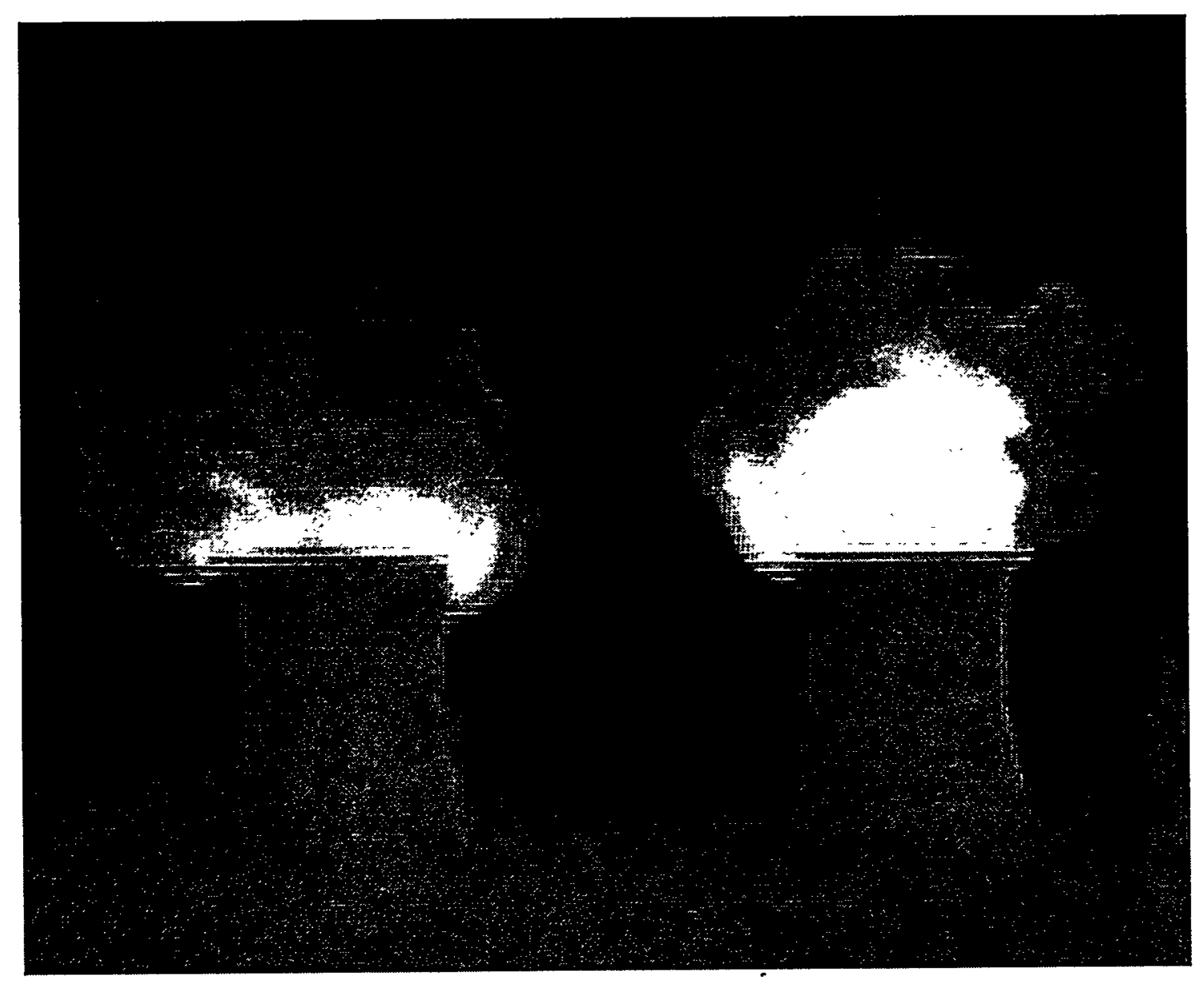

Figure 26. Inframetrics camera image of cooling towers on 3/04/98. 
WSRC-TR-99-00174

May 1999
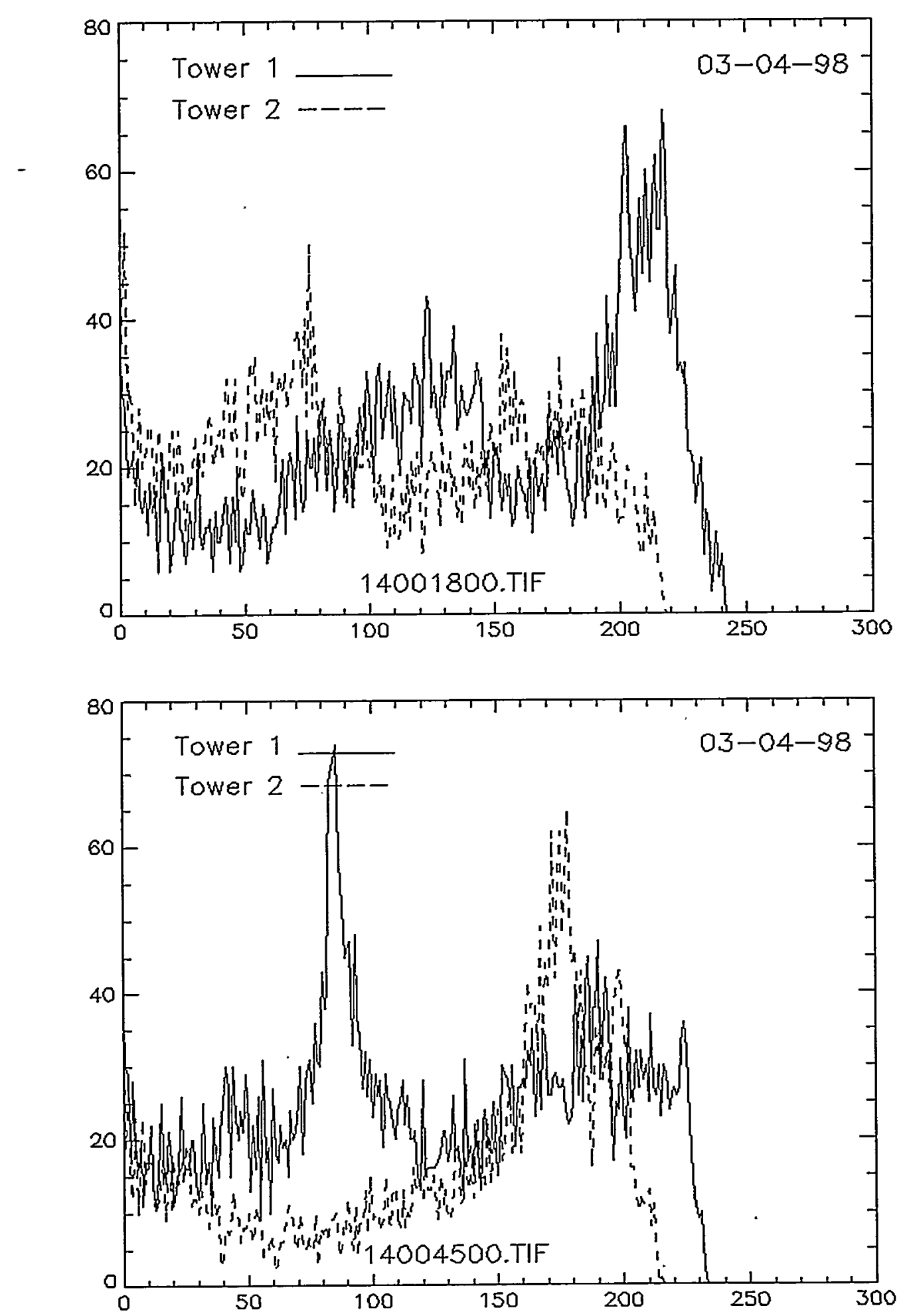

Figure 27. Frequency distributions of Inframetrics camera images of tower plumes. The top figure is based on the plumes in Figure 26. 
WSRC-TR-99-00174

May 1999
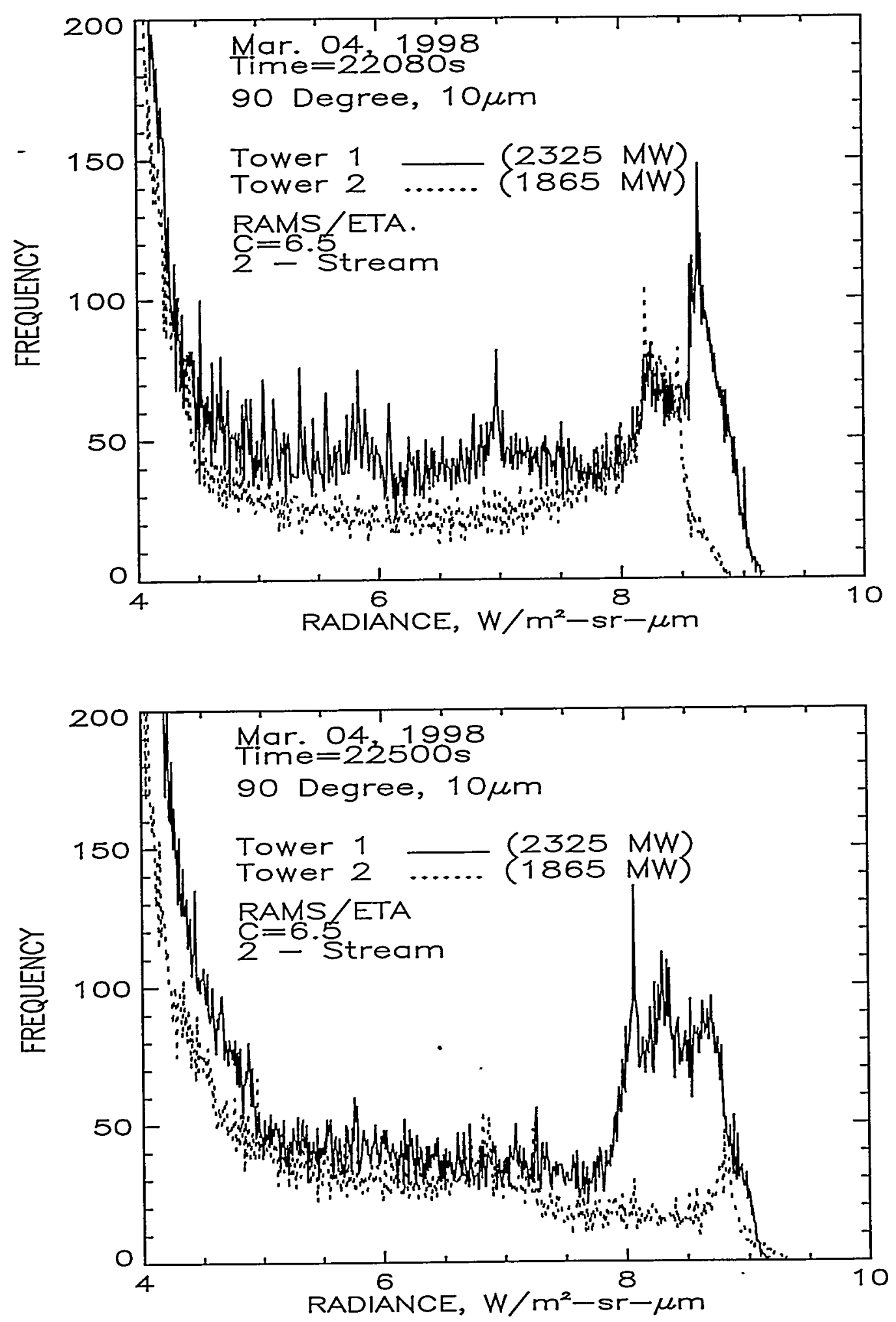

Figure 28. Radiance frequency distributions of simulated plume images. Background radiances are 4.0 (clear sky) and 9.0 (ground). 
WSRC-TR-99-00174

May 1999

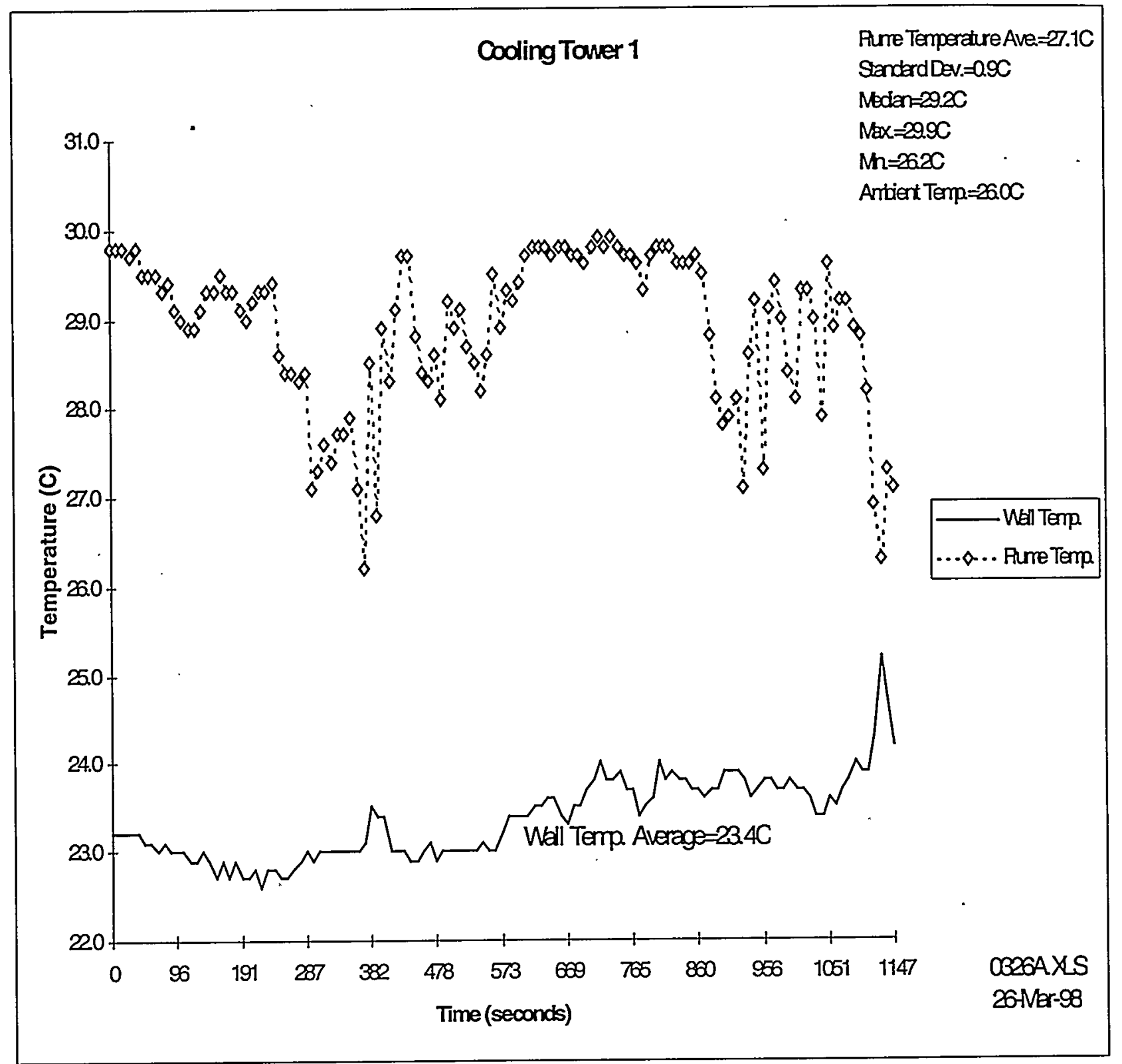

Figure 29. Radiant temperature as measured by Inframetrics camera $(8-12 \mu \mathrm{m})$ at a point just above tower 1 . Data collected on 3/26/98. 


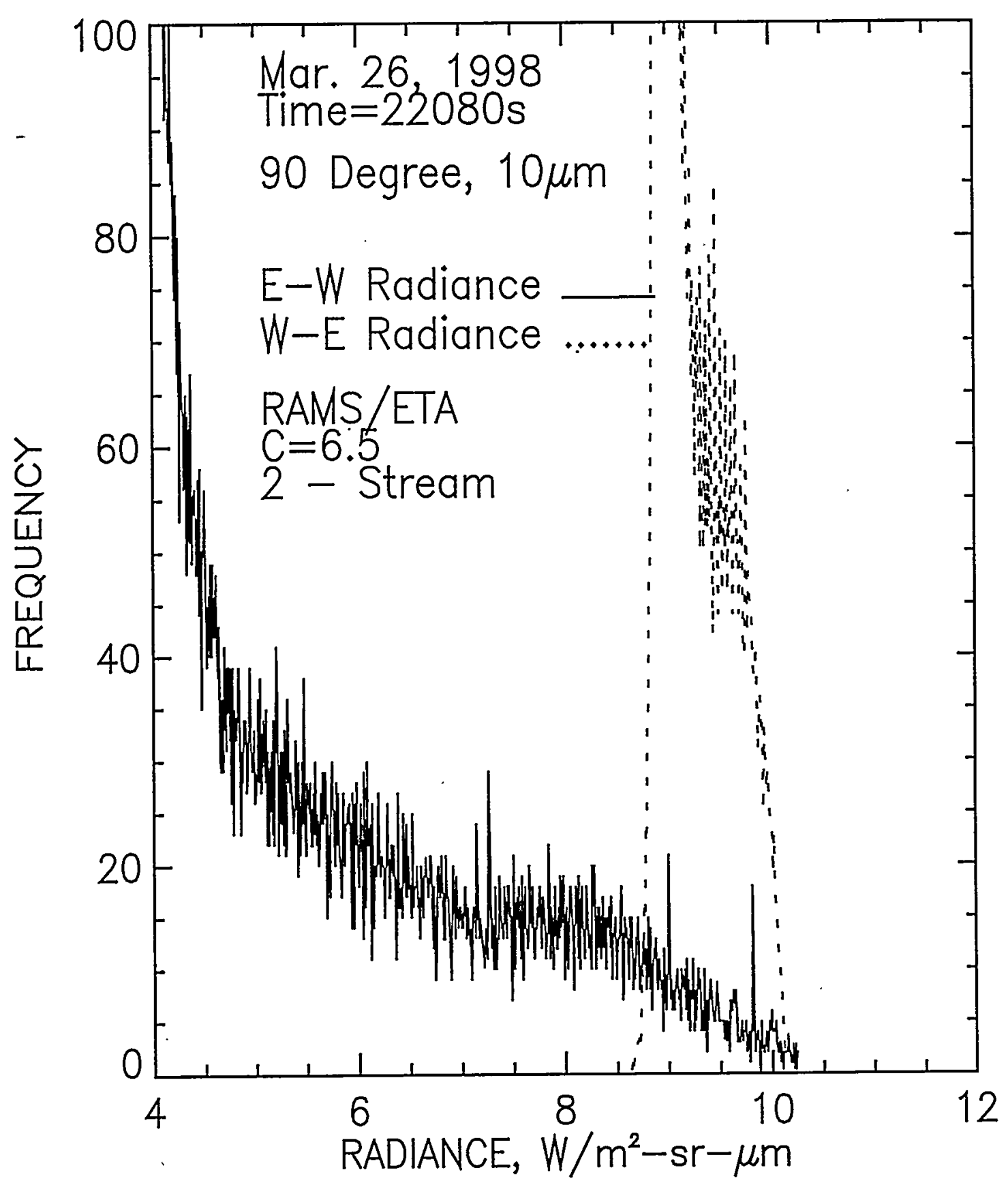

Figure 30. Radiance frequency distributions of simulated plume images for $3 / 26 / 98$. Background radiances are 4.0 (clear sky) and 9.0 (ground). 

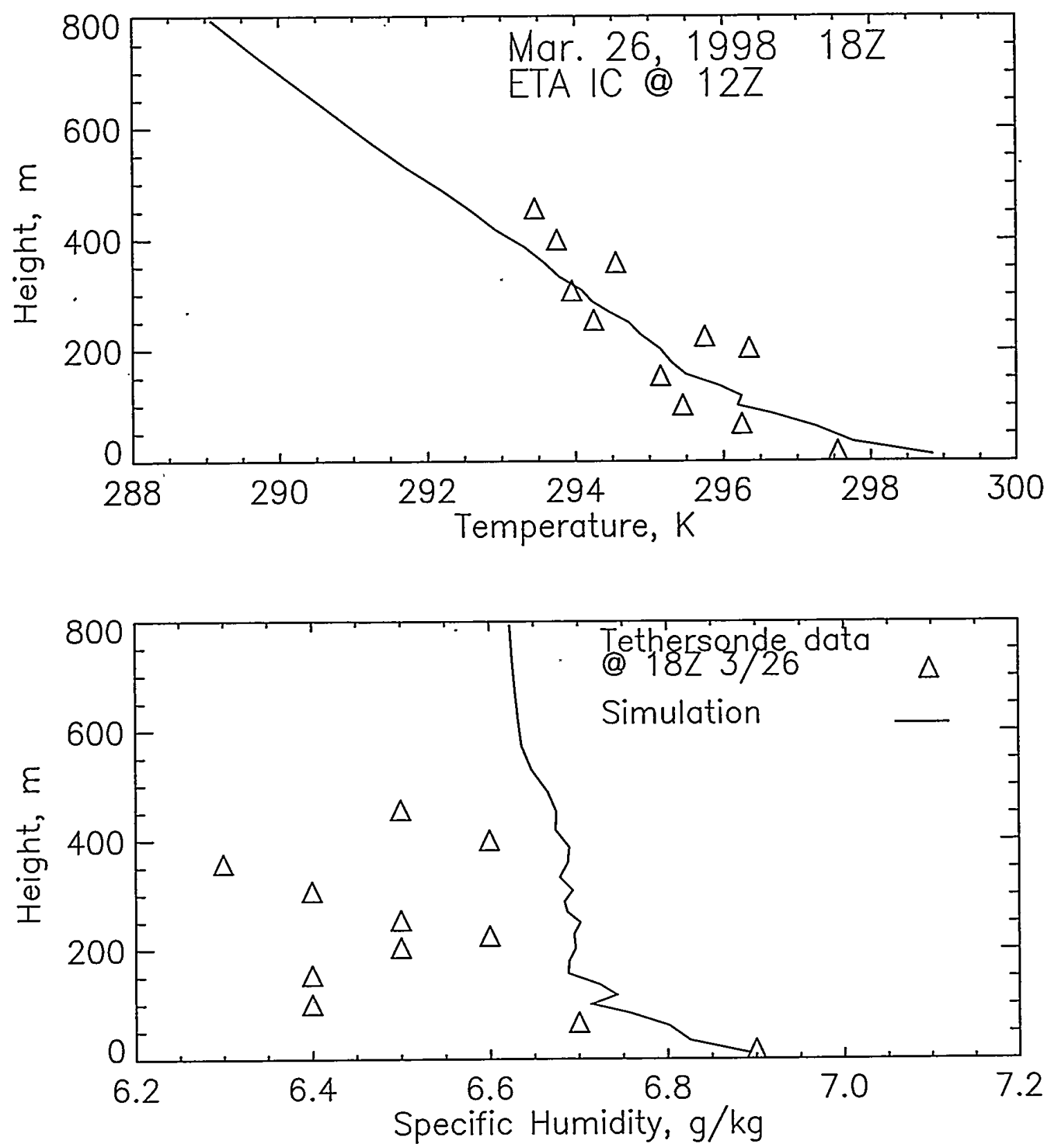

Figure 31. Vertical profiles of temperature and humidity from RAMS simulation and tethersonde data. 
WSRC-TR-99-00174

May 1999
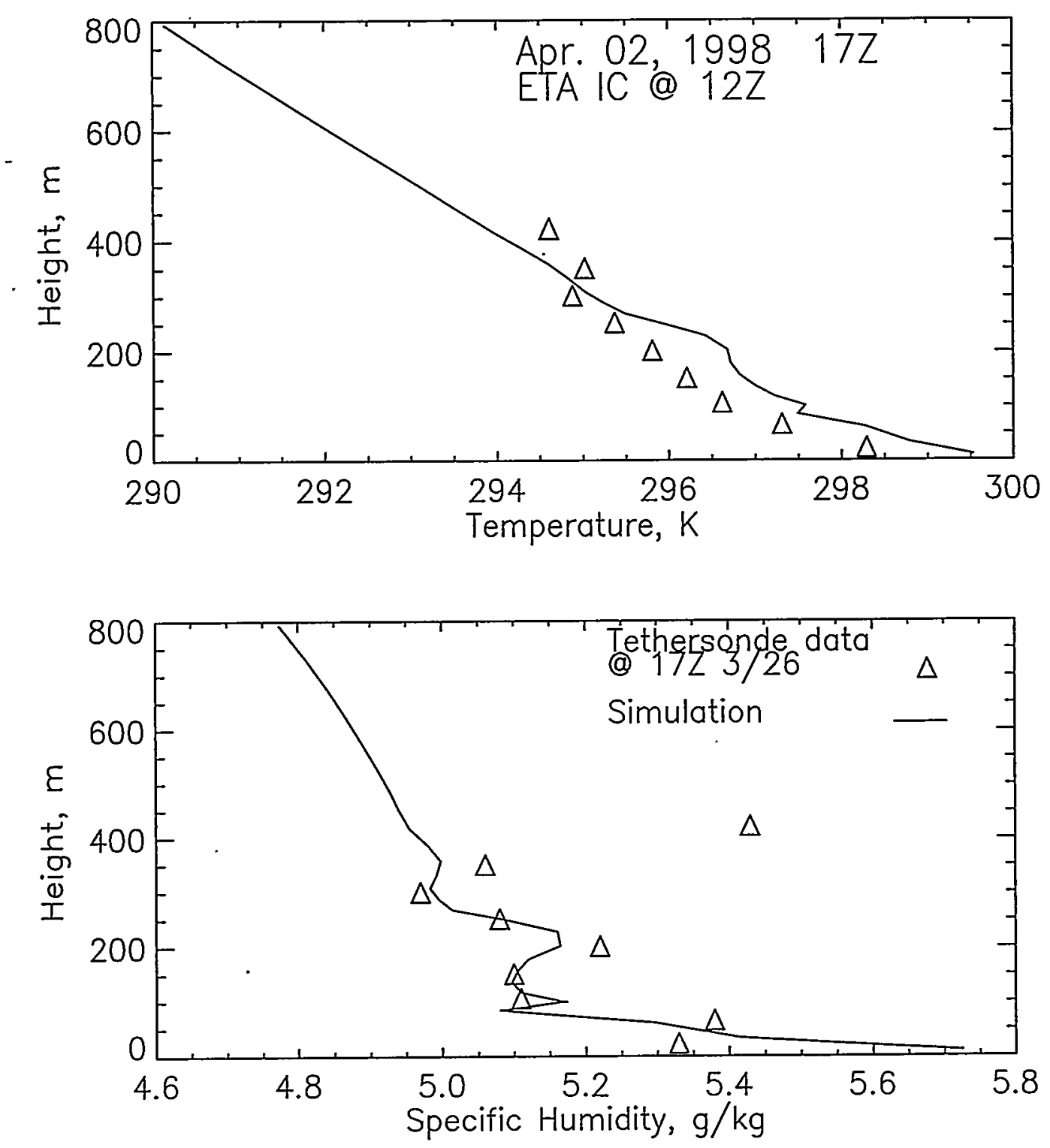

Figure 32. Vertical profiles of temperature and humidity from RAMS simulation and tethersonde data. 
WSRC-TR-99-00174

May 1999
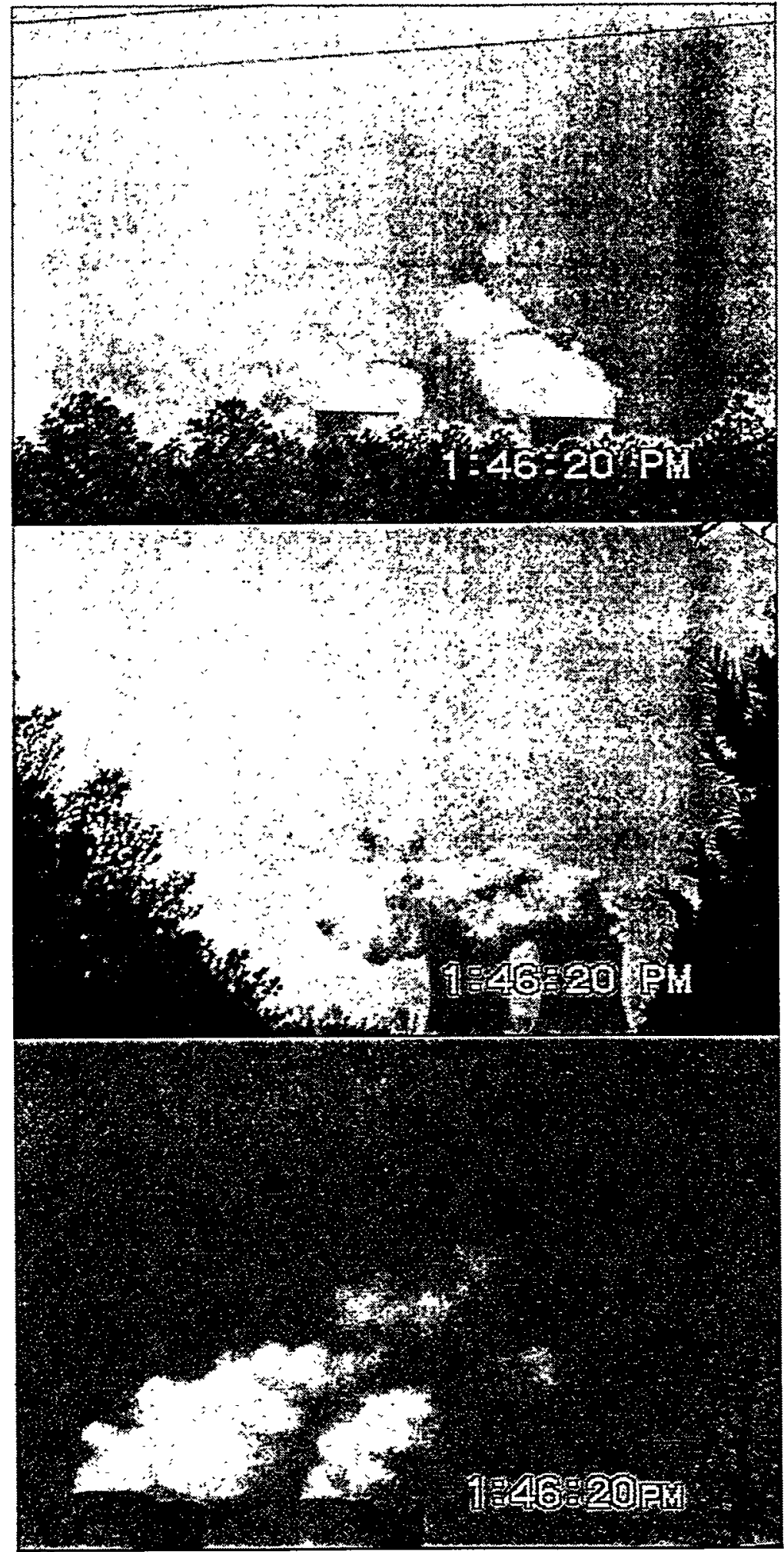

Figure 17. Camcorder images of cooling tower plumes on 2/19/98. 


\section{WSRC-TR-99-00174}

\section{May 1999}

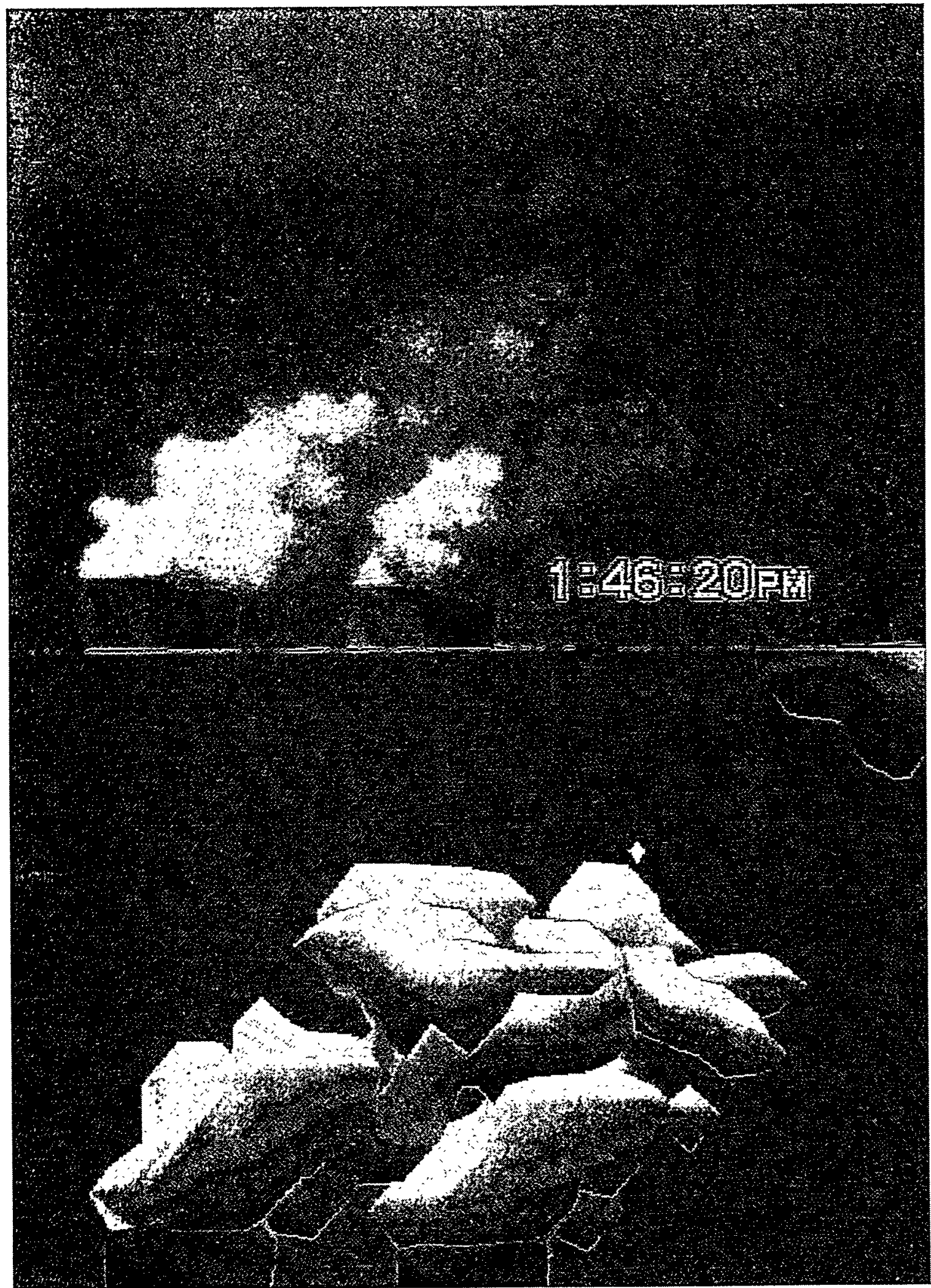

Figure 18. Simulated and observed plumes for $2 / 19 / 98$ collection. 
WSRC-TR-99-00174

May 1999

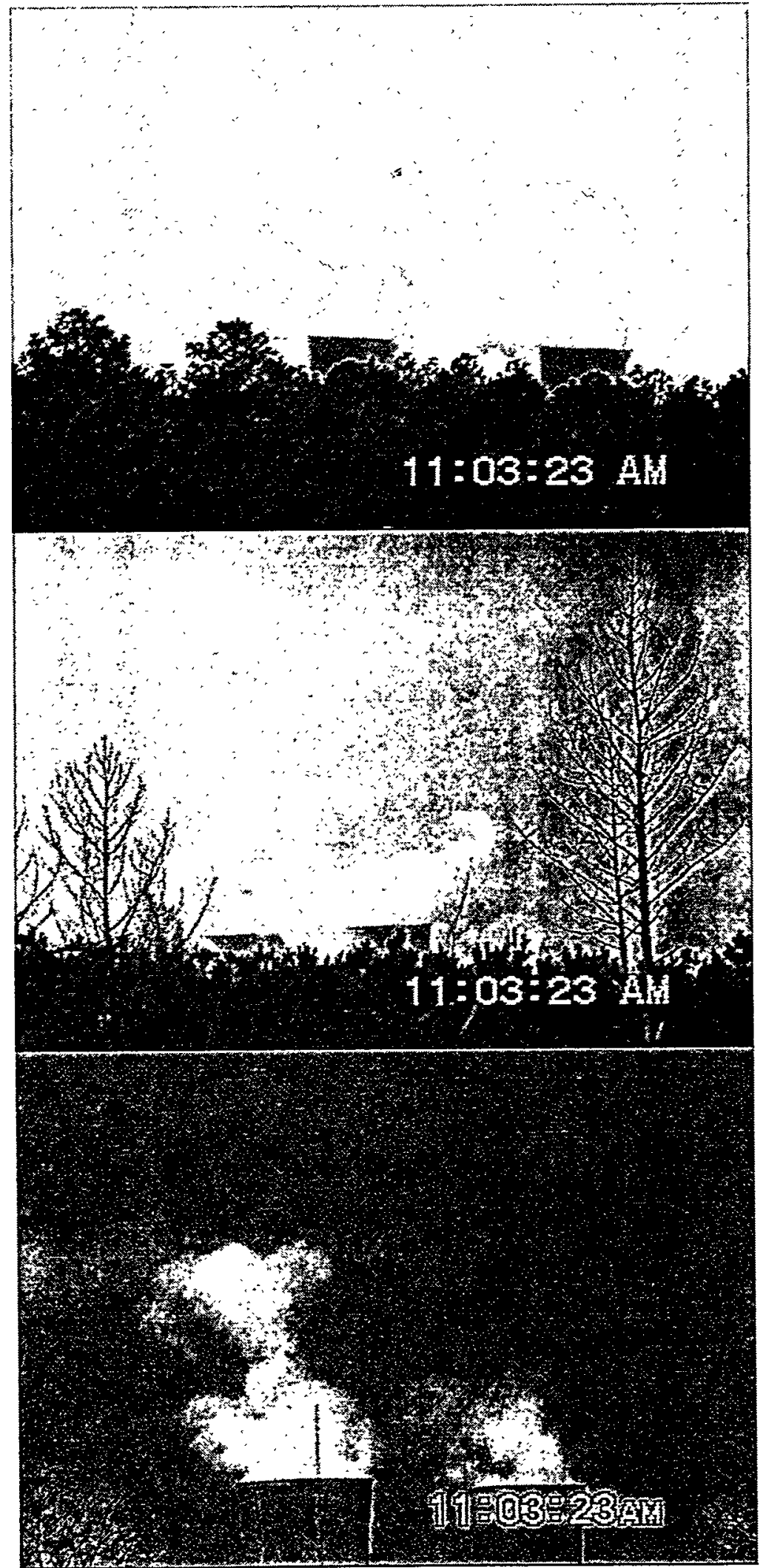

Figure 22. Camcorder images of cooling tower plumes on 2/26/98. 


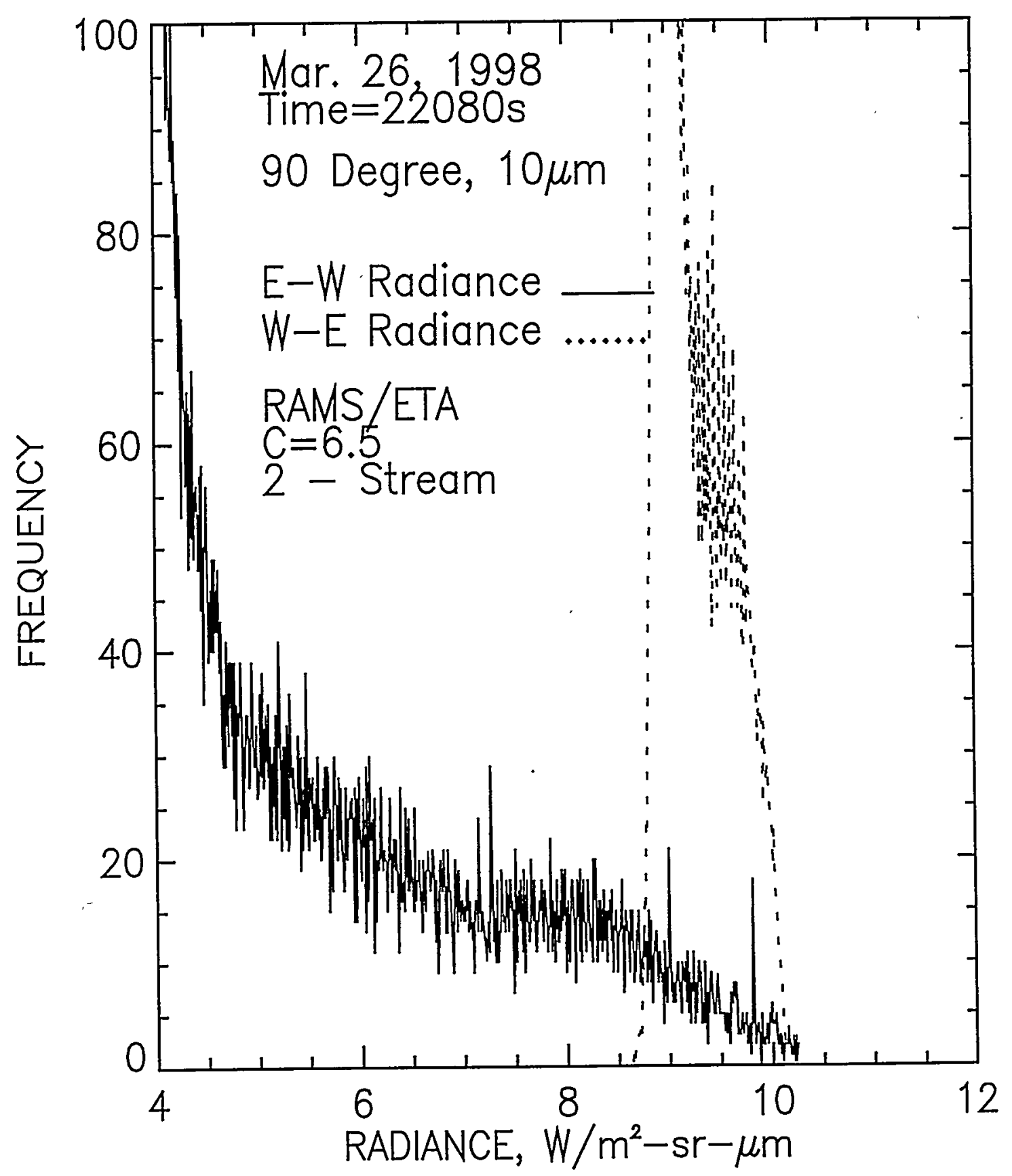

Figure 30. Radiance frequency distributions of simulated plume images for $3 / 26 / 98$. Background radiances are 4.0 (clear sky) and 9.0 (ground). 